\title{
Review Article \\ Stem Cells of Dental Origin: Current Research Trends and Key Milestones towards Clinical Application
}

\author{
Athina Bakopoulou ${ }^{1}$ and Imad About ${ }^{2}$ \\ ${ }^{1}$ Department of Fixed Prosthesis and Implant Prosthodontics, School of Dentistry, Aristotle University of Thessaloniki, \\ Thessaloniki, Greece \\ ${ }^{2}$ Aix-Marseille University, CNRS, Institute of Movement Science (ISM), Marseille, France
}

Correspondence should be addressed to Athina Bakopoulou; abakopoulou@dent.auth.gr

Received 25 May 2016; Accepted 14 September 2016

Academic Editor: Armand Keating

Copyright (C) 2016 A. Bakopoulou and I. About. This is an open access article distributed under the Creative Commons Attribution License, which permits unrestricted use, distribution, and reproduction in any medium, provided the original work is properly cited.

Dental Mesenchymal Stem Cells (MSCs), including Dental Pulp Stem Cells (DPSCs), Stem Cells from Human Exfoliated Deciduous teeth (SHED), and Stem Cells From Apical Papilla (SCAP), have been extensively studied using highly sophisticated in vitro and in vivo systems, yielding substantially improved understanding of their intriguing biological properties. Their capacity to reconstitute various dental and nondental tissues and the inherent angiogenic, neurogenic, and immunomodulatory properties of their secretome have been a subject of meticulous and costly research by various groups over the past decade. Key milestone achievements have exemplified their clinical utility in Regenerative Dentistry, as surrogate therapeutic modules for conventional biomaterial-based approaches, offering regeneration of damaged oral tissues instead of simply "filling the gaps." Thus, the essential next step to validate these immense advances is the implementation of well-designed clinical trials paving the way for exploiting these fascinating research achievements for patient well-being: the ultimate aim of this ground breaking technology. This review paper presents a concise overview of the major biological properties of the human dental MSCs, critical for the translational pathway "from bench to clinic."

\section{Introduction}

A disparate variety of multipotent postnatal or Adult Stem Cells (ASCs) has been identified over the last decade within the oral cavity, raising the intriguing prospect of several alternative therapies in the burgeoning field of Regenerative Dentistry. Oral ASCs can be classified into dental stem cells, encompassing Dental Pulp Stem Cells (DPSCs) [1], Stem Cells from Human Exfoliated Deciduous teeth (SHED) [2], and Stem Cells From Apical Papilla (SCAP) [3, 4], as well as nondental oral SCs, including Dental Follicle Stem Cells (DFSCs) [5], Periodontal Ligament Stem Cells (PDLSCs) [6], Gingival Mesenchymal Stem Cells (GMSCs) [7], Oral Mucosa Stem Cells (OMSCs) found in the lamina propria of adult human gingiva [8], Bone Marrow Mesenchymal Stem Cells (BMMSCs) from orofacial bones [9], PeriosteumDerived Stem Cells (PSCs) [10], and Salivary Gland-Derived Stem Cells (SGSCs) [11]. All these cells are considered as resident in "stem cell niches" of the respective mesenchymal oral tissues and are referred to as mesenchymal stem cells or multipotent mesenchymal stromal cells (MSCs) [12]. In addition to cells derived from healthy tissues, MSCs can also be isolated from damaged oral tissues, such as inflamed pulp $[13,14]$ or periapical cysts [15].

There is substantial evidence suggesting that dental MSCs reside in a quiescent, slow-cycling state in the perivascular niches of human pulp or apical papilla [16]. It has been further shown by means of genetic lineage tracing in rodent incisors that MSCs residing in the dental pulp may be of dual origin, consisting of not only NG2+ pericyte cells, whose presence is closely dependent on tissue vascularity, but also MSCs of nonpericyte origin, contributing to tissue growth and repair [17]. Dental MSCs are thought to originate from the cranial neural crest, expressing both MSC and neuroectodermal SC markers. These cells comply with the minimal criteria stipulated by the International Society of Cellular Therapy (ISCT) in 2006 
[18], including (1) ability to adhere rapidly to plastic culture surfaces, (2) potential for trilineage differentiation towards osteogenic, adipogenic, and chondrogenic phenotypes under the appropriate inductive conditions, and (3) expression of common MSC markers, such as CD105, CD73, and CD90, in conjunction with lack of expression of CD45, CD34, CD14, CD11b, CD79a, CD19, and HLA-DR. Additionally, dental MSCs are characterized by significant population heterogeneity [19], most probably connected to different stages of developmental commitment, reinforced by epigenetic modifications occurring during their ex vivo expansion $[20,21]$. Importantly, recent studies have shown the pivotal role of not only stem/progenitor cells but also nonprogenitor supportive cells, such as injured fibroblasts occurring via secretion of multiple growth factors and complement bioactive fragments in dentin/pulp regeneration processes, revealing the significance of all different cellular components of the heterogeneous population [22-25].

Among the important advantages of dental MSCs compared to other SC sources, such as bone marrow and adipose tissues, are their higher proliferative capacity, facilitating ex vivo expansion in sufficient cell numbers [26, 27]; easy isolation by noninvasive routine clinical procedures (e.g., extraction of impacted third molars or premolars for orthodontic reasons); and the absence, as reported so far, of major adverse reactions, concerning, for example, teratoma formation following in vivo application [28]. Previous studies have shown that DPSCs have the ability to produce singlecell derived Colony Forming Units (CFUs), survive for longer periods without undergoing senescence, and exhibit higher (80-100 times) proliferation rates than BMMSCs [1].

The vast majority of published studies provides evidence on the in vitro multilineage differentiation potential of dental MSCs towards osteo/odontogenic, adipogenic, chondrogenic, neurogenic, angiogenic, and myogenic lineages when grown under defined culture conditions [19, 28]. In vivo studies, mostly in ectopic but less often in orthotopic animal models, have supported their potential to reconstitute functional dentin/pulp complexes when mixed with ceramic substrates (such as, Hydroxyapatite Or Tricalcium Phosphate) $[29,30]$, as well as other tissues, such as bone [31], cementum [32], blood vessels [33-35], and neural tissues [36, 37]. Most recently, attention has been focused on the biological properties of the plethora of soluble trophic and immunomodulatory cytokines produced by dental MSCs (MSC secretome) because of their angiogenic, neurogenic, and tissue repair properties [38]. Additionally, a growing number of preclinical and few clinical "proof-of-concept" studies that have been initiated provide substantial evidence that dental MSCs and/or their secretome can be successfully utilized for dental $[39,40]$ and nondental biomedical applications [41].

Taking all the above into consideration, this review paper aims to provide a concise overview of the major biological properties of the adult dental MSCs (including DPSCs, SHED, and SCAP) which are critical for Tissue Engineering (TE) applications; among these properties being of major interest to the dental community is their inherent potential to regenerate highly vascularized (angiogenesis) and innervated (neurogenesis) soft and hard dental tissues (dentin/pulp complex, alveolar bone). Current research trends and key milestone achievements that exemplify their clinical utility in Regenerative Dentistry will be also highlighted.

\section{Localization and Immunophenotypic Characterization of Dental MSCs}

Dental MSCs abundantly express (>95\% of the cell population) MSC markers, such as, CD90, CD73, and several Cell Adhesion Molecules (CAMs), mainly integrins but also cadherins [42], with the former being responsible for mediating SC adhesion to Extracellular Matrix (ECM) proteins and the latter for cell-cell interactions [43]. Among these, CD29/ b1-integrin, CD49 (subunits b/a $\mathrm{a}_{2}$-integrin, $\mathrm{d} / \mathrm{a}_{4}$-integrin, e/ $\mathrm{a}_{5}$-integrin, and $\mathrm{f} / \mathrm{a}_{6}$-integrin), CD51/a $\mathrm{a}_{\mathrm{v}}$-integrin, CD61/ $\mathrm{b}_{3}$ integrin, and CD166/ALCAM have been found to be variably expressed in different types of dental MSCs, including DPSCs, SHED, and SCAP, further indicating the heterogeneity of these cell populations $[19,28,42]$. Other MSC markers, such as CD146, CD105, CD106, and STRO-1, may show variable expression, dependent on the type and maturity of the dental MSC population and on interindividual variations among various cell donors [44]. In particular, STRO-1, a marker that recognizes a trypsin insensitive epitope on perivascular cells [45], has been used in isolating MSCs populations from human dental pulp [46] and apical papilla [47] with enhanced "stemness" properties and osteo/odontogenic differentiation potential. Immunolocalization studies have, in addition, demonstrated that a subpopulation of SCs coexpressing STRO-1, the perivascular marker CD146 [48] and the pericyte antigen $3 \mathrm{G} 5$, reside in this niche within the adult pulp [16]. Cells expressing another group of markers (STRO1, CD90, CD105, and CD146) were also identified together with the vascular and nerve fibers of the pulp tissue [13]. Most recently, [49] it was shown that ALDH1-, CD90-, and STRO-1-positive cells are located in both perivascular areas and nerve fibers of dental pulps, indicating the possibility of the existence of more than one SC niche. Finally, a recent report [50] identified a rare $(1.5 \%$ by flow cytometry) subpopulation of SCAP, coexpressing NOTCH-3, STRO-1, and CD146, which, according to in situ immunostaining, were associated with blood vessels.

All types of dental MSCs also abundantly express nestin (neural stem cells), while the positive presence of other neural crest SC markers (musashi-1, p75, snail-1, -2, slug, Sox-9, etc.) has been also reported and linked to their embryonic origin [51, 52]. Sakai et al. [53] have also shown that the majority of DPSCs and SHED expressed several neural lineage markers, including nestin, Doublecortin (DCX; neuronal progenitor cells), $\beta$ III-tubulin (early neuronal cells), NeuN (mature neurons), GFAP (neural stem cells and astrocytes), S-100 (Schwann cells), A2B5, and CNPase (oligodendrocyte progenitor cells). Other, less commonly found markers, such as CD44, CD9, CD10, CD13, CD59, and MSCA-1, have also been reported as expressed in DPSCs [54], while CD44 and CD13 are also expressed in SHED [55]. Dental MSCs, including DPSCs [56], SHED [57], and SCAP [58], also show variable but increased expression of embryonic SC markers, 
such as Nanog, Oct3/4, SSEAs (-1, $-3,-4$, and -5$)$, and to a less extent TRA-1-60 and TRA-1-81 [56], as compared to other MSC types [19], such as BMMSCs. Other pluripotency markers, such as SOX-2 and MYC, not normally found in other ASCs, have been reported in tooth germ-derived MSCs [59]. Finally, dental MSCs lack expression of CD45, CD31, HLA-DR, and, in most studies, CD14, while most but not all [60-62] studies have reported absence of expression of CD117 (c-kit) and CD34. Although the ISCT minimal criteria suggest that the absence of CD34 expression is a prerequisite for defining MSCs, more recent studies indicate that CD34 may be expressed in primitive pluripotent stromal stem cells but is progressively eliminated during cell culturing [63]. It has been previously shown that CD34/c-Kit and STRO1 coexpression confirm a neural crest-derived DPSC niche [56], while, in more recent studies [61] two different (STRO1+/c-Kit+/CD34- and STRO-1+/c-Kit+/CD34+) DPSC subpopulations with noticeable differences in their stem cell characteristics have been characterized.

Finally, in a recent study [64], the importance of CD271/NGFR in defining a subpopulation of DPSCs with enhanced odontogenic differentiation potential, as compared to other (CD51/CD140a and STRO-1/CD146) subpopulations also showing odontogenic differentiation capacity, has been emphasized. This is in accordance with studies on BMMSCs showing that CD271/NGFR defines an infrequent but very primitive subset $(<1 \%)$ of the cell population showing enhanced stem cell characteristics [65].

The immunophenotypic characteristics of dental MSCs are summarized in Table 1.

\section{Differentiation Potential and Paracrine Activity of Dental MSCs In Vitro and In Vivo}

3.1. Osteo/Odontogenic Differentiation Potential of Dental MSCs and Regeneration of Dentin/Pulp- and Bone-Like Tissues. One of the most salient characteristics of dental MSCs concerning dental TE applications rests on their odontogenic differentiation potential. Previous studies have shown that dental MSCs, including DPSCs, SHED, and SCAP, have the capacity to differentiate into odontoblastic lineages in vitro and of regenerating dentin/pulp-like complexes or bone-like tissues ectopically and around teeth and implants [29, 31, 66] (the literature summarized in Table 2).

Specifically, DPSCs have demonstrated the capacity to differentiate into odontoblastic-like cells with characteristic cell polarity [67]. When seeded onto dentin, DPSCs may convert into odontoblast-like cells with polarized cell bodies and cellular processes extending into the dentinal tubules [68]. In addition, in recently published work using transcriptome analysis of odontoblasts at different stages of maturity, the p38/MAPK signaling has been identified as the crucial pathway to controlling odontoblast secretory activity and therefore a key molecular target for the therapeutic application of DPSCs [40].

Early reports showed that DPSCs mixed with Hydroxyapatite/Tricalcium Phosphate (HA/TCP) led to the formation of ectopic pulp-dentin-like tissue complexes in immunocompromised mice $[1,6,69]$. Iohara et al. [70] combined 3dimensional cell pellets and Bone Morphogenetic Protein 2 (BMP-2) to induce reparative dentin formation in a dog amputated pulp model. The same group also detailed the possibility of using a subfraction of CD31-/CD146- and CD105+ cells for pulp regeneration $[71,72]$ and in later studies described the effects of Granulocyte-Colony Stimulating Factor (G-CSF) and host age on pulp regeneration [73, 74]. In another study, DPSCs seeded onto collagen scaffolds in presence of Dentin Matrix Protein 1 (DMP-1) induced the formation of a pulpal-like tissue [75]. Similarly, when implanted in enlarged root canals of immunocompromised mice, DPSCs showed the ability to synthesize newly formed dentin and vascularized pulp-like tissue [76], thus providing prospects for utilization of DPSC transplantation for dentin-pulp regeneration.

Other in vivo studies have shown the capacity of DPSCs in bone regeneration in a variety of animal models, including repair of critical-size calvarial defects [77-79] and segmental alveolar defects in a New Zealand rabbit model [80], as well as the capacity for enhancement of implant osteointegration in sites of experimental canine mandibular bone defects [81]. Swine Dental Pulp Stem Cells seeded on TCP scaffolds were also able to regenerate mandibular bone defects in the symphyseal regions of a minipig model [82].

Notably, various scaffolding materials with differing chemical, physical, and mechanical characteristics have been selected for use in pulp/dentin and bone regeneration protocols using dental MSCs, including long-lasting porous bioceramics (e.g., HA, $\beta$-TCP, or bioactive glasses), natural molecules of medium duration (e.g., collagen, chitosan, hyaluronic acid-based hydrogels, and silk fibroin), and shortlife polymers, such as Polyglycolic Acid (PGA), Polylactic Acid (PLA), or their combinations $[39,83]$. In addition, injectable hydrogels (including self-assembling multidomain peptides [84] and a commercial blend Puramatrix ${ }^{\mathrm{TM}}$ ) [85] have been suggested for pulp regeneration in the light of their ability to form nanofibrous matrices under physiological conditions. Recent studies have also proposed demineralized/chemically Treated Dentin Matrices (TDMs) [86] or Cryopreserved Treated Dentine Matrices (CTDM) [87], as ideal biologic scaffolds, because of their combination of favorable mechanical properties and ability to act as a reservoir of dentinogenesis-related growth/morphogenetic factors [88]; this is also validated by in vivo studies [89, 90]. Finally, strategies to improve stem cell/scaffold interfaces also include incorporation of various bioactive molecules [29], as the third component of the TE triad (cells/scaffolds/growth factors). The application of such growth factors without stem cells, in a cell homing versus cell transplantation strategy, has also been suggested as a more clinically translational approach for dentin-pulp regeneration. Based on this concept, ectopic regeneration of dental pulp-like tissues using basic Fibroblast Growth Factor (b-FGF), Vascular Endothelial Growth Factor (VEGF), or Platelet-Derived Growth Factor (PDGF) with a basal set of Nerve Growth Factor (NGF) and Bone Morphogenetic Protein 7 (BMP-7) has been reported [91], while other researches achieved complete pulp regeneration 
TABLE 1: Marker expression in dental MSCs (SHED, DPSCs, and SCAP) and factors identified in their secretomes.

\begin{tabular}{|c|c|c|c|c|}
\hline Dental MSCs & Positive markers & $\begin{array}{l}\text { Negative } \\
\text { markers }\end{array}$ & $\begin{array}{l}\text { Factors in secretome } \\
\text { involved in angiogenesis }\end{array}$ & $\begin{array}{l}\text { Factors in secretome involved in } \\
\text { neurogenesis }\end{array}$ \\
\hline $\begin{array}{l}\text { Stem cells from } \\
\text { Human Exfoliatd } \\
\text { Deciduous teeth } \\
\text { (SHED) }\end{array}$ & $\begin{array}{l}\text { CD90, CD73, CD105, CD146, } \\
\text { STRO-1, CD44, CD13 } \\
\text { Nestin, DCX, } \beta \text { III-tubulin, NeuN, } \\
\text { GFAP, S-100, A2B5, CNPase } \\
\text { Nanog, Oct3/4, SSEAs }(-3,-4)\end{array}$ & $\begin{array}{l}\text { CD11b } \\
\text { CD45 } \\
\text { CD34 } \\
\text { CD14 } \\
\text { CD19 } \\
\text { CD43 }\end{array}$ & $\begin{array}{l}\text { VEGF-A, VEGF-C, } \\
\text { EG-VEGF (PK-1), HGF, } \\
\text { IGF-1, FGF-2, SDF-1, } \\
\text { SCF, EGF, TIMP-1, -2, } \\
\text { MMP-2, -3, -9, MCP-1, } \\
\text { ANG, TGF-b }\end{array}$ & $\begin{array}{l}\text { BDNF, GDNF, MCP-1, } \\
\text { ED-Siglec-9, IL-6, NRCAM, } \\
\text { GDF-15, NCAM-1, TACE, } \\
\text { Nidogen-1 NRG-1, TIMP-1, -2, } \\
\text { HGF, SCF, MMP-2, -3, -9, } \\
\text { decorin, IL-22, IL28A, IL-29, } \\
\text { osteopontin, SCF, ANG, } \\
\text { VEGF-A, EG-VEGF, VEGF-C, } \\
\text { growth hormone, insulin, PIGF, } \\
\text { TGF-b }\end{array}$ \\
\hline $\begin{array}{l}\text { Dental Pulp Stem } \\
\text { Cells (DPSCs) }\end{array}$ & $\begin{array}{l}\text { CD90, CD73, CD105, CD146, } \\
\text { STRO-1, CD106, CD29, CD49, } \\
\text { CD51, CD61, CD166, ALDH1, 3G5, } \\
\text { CD44, CD9, CD10 CD13, CD59, } \\
\text { MSCA-1, CD81, CD24 } \\
\text { CD271/NGFR, Nestin, DCX, } \\
\beta \text { III-tubulin, NeuN, GFAP, S-100, } \\
\text { A2B5, CNPase, musashi-1, p75, } \\
\text { snail-1, -2, slug, Sox-9 } \\
\text { Nanog, Oct3/4, SSEAs (-1, -3, -4, } \\
\text {-5), Notch-1, -2, -3 }\end{array}$ & $\begin{array}{c}\text { CD45 } \\
\text { CD34 } \\
\text { CD14, } \\
\text { CD19 CD31, } \\
\text { CD117, CD133 } \\
\text { HLA-DR }\end{array}$ & $\begin{array}{l}\text { VEGF, uPA, IL-8, TSP-1, } \\
\text { IGFBP-3, TIMP-1, -4, } \\
\text { MMP-9, PAI-1 (serpin } \\
\text { E1), endostatin, } \\
\text { ANGPT-1, ANG, DPPIV, } \\
\text { EDN-1, PTX-3, PEDF } \\
\text { (serpin F1), PDGF-AA } \\
\text { and PDGF-AB/BB, } \\
\text { MCP-1 }\end{array}$ & $\begin{array}{l}\text { NGF, BDNF, NT-3, CNTF, } \\
\text { GDNF, MCP-1, VEGF, FGF-2, } \\
\text { PDGF-AA and PDGF-AB/BB, } \\
\text { MMP-9, ANG, TIMP-1, -4 }\end{array}$ \\
\hline $\begin{array}{l}\text { Stem Cells from } \\
\text { Apical Papilla (SCAP) }\end{array}$ & $\begin{array}{l}\text { CD90, CD73, CD105, CD146, } \\
\text { STRO-1, CD106, CD29, CD49, } \\
\text { CD51, CD61, CD166, ALDH1, 3G5, } \\
\text { CD44, CD9, CD10 CD13, CD59, } \\
\text { MSCA-1, CD34, CD81, CD24, c-Kit } \\
\text { CD271/NGFR, Nestin, NSE, } \\
\text { CNPase, musashi-1, p75, snail-1, -2, } \\
\text { slug, Sox-9 } \\
\text { Nanog, Oct3/4, SSEAs (-1, -3, -4, } \\
\text {-5), TRA-1-60-, TRA-1-81, Notch -2, } \\
-3\end{array}$ & $\begin{array}{l}\text { CD14 } \\
\text { CD18 } \\
\text { CD34 } \\
\text { CD45 } \\
\text { CD117 } \\
\text { CD150 }\end{array}$ & $\begin{array}{l}\text { ANGPT-1, ANG, DPPIV, } \\
\text { EDN-1, PTX-3, PEDF } \\
\text { (serpin F1), IGFBP-1, -2, } \\
\text {-3, TIMP-1, -4, TSP-1, } \\
\text { VEGF, uPA, Activin A, } \\
\text { HGF, FGF-7, PIGF } \\
\text { (serpin E1), TGFb, } \\
\text { CXCL-16, persephin, } \\
\text { NRG1-b1, MCP-1 }\end{array}$ & $\begin{array}{l}\text { MDK, NEGF-1 (PTN), NEGF-2, } \\
\text { CXCR4, MANF, AHNAK, NRP2, } \\
\text { ANG, TIMP-1, -4, CXCL-16, } \\
\text { NRG1-b1, MCP-1 }\end{array}$ \\
\hline
\end{tabular}

TABLE 2: Key references on the osteo/odontogenic, angiogenic, and neurogenic differentiation potential of dental MSCs in vitro and in vivo.

\begin{tabular}{|c|c|c|c|c|c|c|}
\hline \multirow[t]{2}{*}{ Dental MSCs } & \multicolumn{2}{|c|}{$\begin{array}{l}\text { Osteo/odontogenic } \\
\text { differentiation }\end{array}$} & \multicolumn{2}{|c|}{ Angiogenic differentiation } & \multicolumn{2}{|c|}{ Neurogenic differentiation } \\
\hline & In vitro & $\begin{array}{l}\text { In vitro and/or } \\
\text { in vivo (bone or } \\
\text { dentin/pulp) }\end{array}$ & In vitro & $\begin{array}{c}\text { In vitro and/or } \\
\text { in vivo }\end{array}$ & In vitro & $\begin{array}{c}\text { In vitro and/or } \\
\text { in vivo }\end{array}$ \\
\hline $\begin{array}{l}\text { Stem cells from } \\
\text { Human } \\
\text { Exfoliated } \\
\text { Deciduous teeth } \\
\text { (SHED) }\end{array}$ & {$[26,98]$} & $\begin{array}{c}{[2,53,55,60,67} \\
82,85,89,90 \\
93-95]\end{array}$ & {$[67]$} & {$[119,120]$} & {$[57,67,142,143]$} & {$[36,53,148,150]$} \\
\hline $\begin{array}{l}\text { Dental Pulp } \\
\text { Stem Cells } \\
\text { (DPSCs) }\end{array}$ & $\begin{array}{c}14,21,26,49 \\
51,54,59,61,88 \\
97,123]\end{array}$ & $\begin{array}{c}{[1,13,53,55,56} \\
62,67,69- \\
81,84,113,114]\end{array}$ & $\begin{array}{c}{[51,59,67,115} \\
123]\end{array}$ & $\begin{array}{c}62,116- \\
118,121,122,126- \\
128] \\
\end{array}$ & $\begin{array}{c}51,54,59,61 \\
67,135- \\
139,143,144,147] \\
\end{array}$ & $\begin{array}{c}{[53,56,116,140} \\
141,151,152]\end{array}$ \\
\hline $\begin{array}{l}\text { Stem Cells from } \\
\text { Apical Papilla } \\
\text { (SCAP) }\end{array}$ & $\begin{array}{c}4,44,47,50, \\
97,98,102,104- \\
106,108,110-112]\end{array}$ & $\begin{array}{c}{[52,76,99-} \\
101,103,106,109]\end{array}$ & {$[58,124,125]$} & {$[121]$} & {$[47,52,144]$} & {$[145,146]$} \\
\hline
\end{tabular}

in pulpectomized mature dog teeth by using a stromal cell-derived factor-1a- (SDF-1a-) loaded silk fibroin scaffold without DPSC transplantation [92].

Significant similarities, but also differences in osteo/ odontogenic differentiation potential, have been reported for SHED. Pivotal studies by Miura et al. [2] showed that SHED are characterized by osteoinductive capacity in vivo, but only a quarter of the clones showed potential to generate ectopic dentin-like tissue. SHED were also able to form an osteoinductive template in immunocompromised mice, 
inducing the recruitment of host murine osteogenic cells to repair critically sized calvarial defects [93]. Recently, it was shown that both DPSCs and SHED combined with PlateletRich Plasma (PRP) were able to regenerate vascularized bone tissue around dental implants in dog and puppy models, respectively [55]. Recent reports have also shown that 5year cryopreserved SHED were still able to proliferate and undergo osteogenesis without immune reaction in a $9 \mathrm{~mm}$ mandibular defect in dogs [94] and to enhance mandibular distraction osteogenesis in a rabbit model [95].

Despite those studies showing the preferential osteogenic versus odontogenic differentiation potential of SHED, other studies also report that SHED are capable of differentiating into functional odontoblasts in vitro [2] and of regenerating a tissue with architecture and cellularity resembling the physiologic dental pulp when seeded in biodegradable scaffolds prepared within human tooth slices and transplanted into immunodeficient mice [89]. It has been recently shown that SHED can generate functional dental pulp when injected with scaffolds (Puramatrix or rhCollagen) into full-length root canals [85].

A very recent and interesting study mapping potential molecular differences between SHED and DPSCs identified several differentially regulated genes [96]. Among these high-mobility group AT-hook 2 (HMGA-2) protein, a stem cell-associated marker, together with several proliferationrelated genes showed a robust expression in SHED, while ECM genes, such as collagen I, fibronectin, and signaling molecules, such as VEGF, Fibroblast Growth Factor Receptor 1 (FGFR-1), and Insulin Growth Factor Receptor 1 (IGFR-1) were upregulated in DPSCs, suggesting that SHED are more competent in self-renewal and proliferation and DPSCs in signaling and matrix synthesis.

Finally, SCAP appear as a cell population similar to, but significantly different from, DPSCs [97]. Although the apical papilla is the precursor tissue of the radicular pulp [18], it is an anatomically distinct area separated by a cell-rich zone. SCAP have been reported to display a higher proliferation rate, number of population doublings, dental tissue regeneration capacity, and STRO-1 expression in comparison with DPSCs [68]. In addition, SCAP have shown a higher expression of survivin and telomerase, two proteins critical for cell proliferation [4]. In contrast, SCAP have been shown to express lower levels of markers, such as Dentin Sialoprotein (DSP), Matrix Extracellular Phosphoglycoprotein (MEPE), transforming growth factor receptor II (TGFbRII), and Vascular Endothelial Growth Factor receptor I (VEGFR1) compared to DPSCs [19]. A recent study demonstrated significant variations in the mineral composition of mineralized tissues produced in vitro by various types of dental MSCs [98]. SCAP and SHED produced a more highly mineralized matrix in comparison with DPSCs but with lower crystallinity and carbonate substitution.

Studies have indicated that SCAP are capable of differentiating into odontoblastic-like cells [97] and osteogenic cells [99] in vitro and into vascularized dentin/pulp-like complexes, after transplantation into immunodeficient mice, in an appropriate carrier substrate [4, 68]. Additionally, transplantation of SCAP inside a root-shaped HA/TCP block coated with PDLSCs into the extraction socket of a minipig lower incisor demonstrated the successful regeneration of the root/periodontal structure over which a porcelain crown has been placed [100]. Furthermore, SCAP could generate cement/woven bone-like tissue with embedded cementocytes/bone-like cells; however, the precise nature of the mineralized tissue produced was not identified [101].

Although SCAP have not been so closely investigated as DPSCs, several later reports provide significant insight into the particular molecular mechanisms responsible for SCAP biological responses to various microenvironments, providing data pivotally useful for the design of future regenerative strategies for targeted dental TE. Among key inductive factors demonstrated to exhibit a major role in SCAP osteo/ odontogenic differentiation are BMP-2 [102], BMP-9 [103], and the conjunction of BMP-2 and VEGF [104]. Other studies have highlighted the importance of Nuclear Factor I-C (NFIC) known to be involved in the regulation of root development [105] and its regulatory interaction with transforming growth factor- $\beta 1$ (TGF- $\beta 1$ ) in inducing odontogenic transformation of SCAP [106]. In a recent study, Plasminogen activator Inhibitor 1 (PAI-1), has been suggested as pivotal factor in inducing odontogenic differentiation of SCAP [107]. Finally, a number of studies have also closely studied the signaling pathways regulating odontogenic differentiation of SCAP; among these, differential activation of ALK5/Smad2 and MEK/ERK [108], canonical Wnt synergistic with BMP-9 [109], Notch [110], canonical NF- $\kappa$ B [111], and ERK and JNK signaling pathways in combination with a mechanical stress stimulus have been indicated as having a paramount role in the committed differentiation of SCAP [112].

It must be noted that a major problem concerning in vivo studies aiming at regenerating functional dentin-pulp complexes or bone around teeth and implants is the fact that the majority have been conducted in ectopic implantation models, mostly subcutaneously into immunocompromised mice $[13,29,67,76]$, and to a less extent in renal capsules of rats [113]. In contrast, only few attempts in orthotropic largeanimal models (dogs or mini pigs) have been performed by a sole research group [70-73], probably in view of the considerable economic costs involved together with the ethical issues associated with animal welfare. Most recently, a root implant model in minipigs involving the middle sections of roots from freshly extracted swine incisors filled with scaffolds containing DPSCs and then implanted into the fresh postextraction sockets has been designed. This provided a valuable animal (although not really orthotopic) model simulating clinical situations [114].

Current pulp regeneration protocols have also been recently systematically reviewed by Fawzy El-Sayed et al. [30]. From 1364 screened articles the authors selected five studies for the quantitative analysis complying to specific inclusion/ exclusion criteria. They revealed that stem cell transplantation was linked with significantly greater regenerated pulp and dentin per root canal total area when compared with controls. A solitary study reported on capillaries/nerves per unit surface area and found that the density of both nerves and capillaries was noticeably greater in stem/progenitor celltransplanted pulps compared with controls [72]. The authors 
emphasized the paucity of quantitative evaluations of the amount of regenerated tissue and the lack of consensus about defining the primary outcomes of the regenerative procedures, including neural, vascular, soft, or hard tissue/dentinal regeneration as the primary limitation of the majority of in vivo studies. It was also mentioned that conclusions were drawn on the basis of histological assessments without additional functional innervation and vascularization tests to provide a more comprehensive assessment of functional pulp/dentin regeneration. Interestingly, the majority of studies showed a high risk of selection, performance, detection, and reporting bias. The main causes of this bias were attributed to the fact that none of the studies had performed sample size calculations to enhance statistical power, while lack of standardization of the animal models and type of experimental defects was a cause of significant heterogeneity. In addition, no split-mouth designs were applied, while clustering of statistical units within the same animal was a common practice. Finally, randomization of treatments and blinding of examiners were reported in very few studies.

\subsection{Angiogenic Properties of Dental MSCs}

3.2.1. Endothelial Transdifferentiation Potential of Dental MSCs. Encouraged by the exceptional "plasticity" of dental MSCs, a limited number of studies have attempted to investigate the endothelial transdifferentiation potential of DPSCs $[51,62,115-118]$, SHED $[119,120]$, and SCAP $[58,121]$ in the presence of specialized angiogenesis-inductive media (summarized in Table 2). The endothelial shift of MSCs in these studies is mainly indicated by the upregulation of typical endothelial cell (EC) markers, such as PECAM-1, VEGFR-2, vWF, and VE-cadherin and further evidenced by functional assays, such as ability to form capillary-like structures on Matrigel or other matrices or by uptake of Acetylated-Low Density LipoProtein Lipase (Ac-LPL), but also by various in vivo assays, including mouse Matrigel assays and Chicken Chorioallantoic Membrane (CAM) assays [33, 34, 122].

According to the in vitro studies, coculture of DPSCs [123] or SCAP [124] with ECs significantly improved the angiogenic potential of ECs, especially under hypoxic conditions $[124,125]$. SHED differentiation into VEGFR-2/CD31 positive EC-like cells has been shown through a VEGF/MEK-1/ERK signaling pathway [120]. Moreover, a VEGFR-2-dependent function of murine DPSCs as pericyte-like cells has been substantiated, since a shRNA knockdown of VEGFR-2 produced a decreased expression of VEGFA, VEGF receptors, and Ephrin B-2 and reduced vascular density of Matrigel plugs in vivo [118]. Finally, short-term exposure of SCAP to serum, glucose, and oxygen deprivation (SGOD) conditions has been shown to be potent in eliciting a proangiogenesis program, as evidenced by activation of VEGF/VEGFR and Angiopoietins/Tie pathways [58]. These results confirm that dental MSCs can actually show considerable adaptability to severely adverse microenvironmental conditions, by undergoing a rapid endothelial shift rather than activating apoptosis.

Despite encouraging data, most of the above-mentioned studies actually indicate but fail to prove a functional and homogenous in vitro differentiation of MSCs into ECs, suggesting that it might be inaccurate to designate EC-switched MSCs as mature ECs, but rather as an intermediate EC-like population, primarily supporting typical functions of mature ECs or mainly acting in a paracrine way (as analyzed below). Thus, identification of additional microenvironmental cues as well a more detailed understanding of the molecular mechanisms responsible for skewing dental MSCs into mature ECs could constitute a critical step for utilizing them as neoangiogenesis sources in TE.

In addition to in vitro data, additional evidence from in vivo studies could show that SHED differentiate into ECs when seeded in biodegradable scaffolds and transplanted into immunodeficient mice [89]. DPSCs alone or primarily in coculture with Human Umbilical Vein Endothelial Cells (HUVEC) when encapsulated in three-dimensional peptide hydrogel matrices (PuraMatrix) were able to support cell survival, migration, and capillary network formation and to regenerate vascularized pulp-like tissue after transplantation in mice [126]. Iohara et al. [127] were able to isolate and characterize a highly vasculogenic subfraction of side population (SP) of CD31-/CD146- porcine tooth germ-derived dental MSCs, while in later study the CD31- pulp fraction was used successfully to reconstitute blood flow and capillary density in a mouse hindlimb ischemia model, to induce neurogenesis in a cerebral ischemia model, and finally to reinstitute a vascularized pulp in an ectopic root transplantation model [116]. Similar results were reported for human DPSCs, which showed ability to induce angiogenesis and reduce infarct size in a myocardial infarction rat model [128].

3.2.2. Angiogenic Properties of Dental MSC Secretome. Despite encouraging data on the endothelial transdifferentiation potential of dental MSCs, significant lines of evidence indicate that the rate of MSC engraftment after local or systemic delivery in vivo remains problematically low at $<10 \%$ [129]. This contrasts with several other lines of evidence suggesting that the angiogenic effects of MSCs are primarily derived from secretion of several soluble factors, such as growth factors, cytokines, chemokines, Extracellular Matrix proteins and proteases, or even genetic material [130] as a response to various microenvironmental cues (summarized in Table 1), rather than their endothelial transdifferentiation. There is growing interest in the investigation of MSC "secretome" with the increasing recognition of the paracrine/autocrine role of MSCs to many biological functions, including cell proliferation, differentiation, signaling, apoptosis, angiogenesis, and neurogenesis. Furthermore, the use of cell-free approaches offers several advantages with respect to concerns related to immunogenicity, tumorigenicity, and transmission of infections, which, although currently considered very low for autologous therapies with adult MSCs, are still under investigation in "proof-of-concept" clinical studies being underway in various fields of Medicine and Dentistry.

Dental MSCs (DPSCs and SCAP) have been shown by recent studies to secrete, under various stress conditions, several pro- and antiangiogenetic factors able to stimulate endothelial motility and function $[58,121]$. In particular, it has 
been shown that DPSCs secrete several proangiogenic factors (VEGF, Monocyte Chemotactic Protein 1- (MCP-1), IL-8, Insulin-Like Growth Factor Binding Protein 3 (IGFBP-3), and Urokinase Plasminogen Activator (uPA)) and antiangiogenic factors (Tissue Inhibitor Of Metalloproteinase 1 (TIMP1), Plasminogen Activator Inhibitor-1 (PAI-1), endostatin, and Thrombospondin-1 (TSP-1)), under serum deprivation conditions [117], while in a later study by the same group differential angiogenic secretome expression was observed among various dental MSC types, including DPSCs, SCAP, and DFSCs [121]. Interestingly, DPSCs and SCAP elicited a predominant proangiogenic effect in vitro and in vivo compared to DFSCs, which renders them an attractive cell source for angiogenesis applications. Subsequently, it has been shown that, under serum, glucose, and oxygen deprivation (SGOD) conditions, SCAP release higher numbers and amounts of proangiogenic factors (Angiogenin, IGFBP3 , and VEGF) and lower amounts of antiangiogenic factors (Serpin-E1, TIMP-1, and TSP-1) in comparison with SOD or $\mathrm{SD}$ alone, providing insights into the optimal preconditioning strategies for SC-based treatment of damaged/ischemic tissues [58]. Most recently, SCAP secretome has been extensively profiled [131]; it was found that a total of 2,046 proteins are released, including chemokines, angiogenic, immunomodulatory, antiapoptotic, and neuroprotective factors, and ECM proteins. SCAP secreted significantly larger amounts of chemokines and neurotrophins than BMMSCs, whereas BMMSCs secreted more ECM proteins and proangiogenic factors.

It is significant to note that secretion of various soluble factors by MSCs may occur either via exocytosis or via release of extracellular vesicles (EVs). These include either exosomes (30-100 $\mathrm{nm}$ in size, originating from intracellular microvesicles) or microvesicles (100-1000 nm in size, originating from the plasma membranes) [132]. A recent study showed that DPSC-derived exosomes suppress carrageenaninduced acute inflammation in mice [133]. This was among other reasons attributed to the fact that SHED exosomes contain annexin $\mathrm{A} 1$ that acts as mediator of the antimigratory effects of glucocorticoids, thereby suppressing edema formation.

\subsection{Neurogenic Properties of Dental MSCs}

3.3.1. Neurogenic Transdifferentiation Potential of Dental MSCs. Numerous studies so far have highlighted the inherent neurogenic differentiation potential of dental MSCs (summarized in Table 2), attributed to their neural crest embryonic origin [134]. DPSCs [51, 135-141], SHED [36, $57,142,143]$, and SCAP $[4,47,125,144-146]$ have shown enhanced potential for differentiation into a variety of neural lineages, including functionally active dopaminergic cells and glial cells, leading proposals for dental MSCs to be used for regenerative therapy of several neurodegenerative diseases [37]. Notably, dental MSCs, while still in an undifferentiated state, constitutively express markers of neural stem/progenitor, as well as mature neural cells, including SOX-2, tenascin C, ENO-2, MAP2ab, c-FOS, Nestin, Neurofilament (NEF-H and NEF-L), Glial Fibrillary Acidic
Protein (GFAP), bIII-tubulin, Microtubule-Associated Protein 2 (MAP-2), and many others [143]. However, the data regarding the neural differentiation potential of dental MSCs seem to vary for different cell types and their subpopulations in the vast body of studies published to date [37], preventing safe comparative conclusions regarding the superiority of any one cell type in regenerating neural tissues.

An overview of existing literature actually reveals the wide range of diversity encountered in the neural differentiation protocols used so far by different research groups. This complexity is connected to (1) the culture microenvironment, (2) the application of either single- or in most recent studies multiple-stage differentiation protocols often alternating cell suspension (in the form of spheroids/neurospheres) with adherent cell culture systems, and (3) the biological endpoints explored by each study.

Regarding the cell culture conditions, a variety of substrates, predominantly poly-l-lysine $[36,57,140]$, poly-1ornithine with/without lamin [147], gelatin [4, 47], and more rarely other substrates, have been used, while in most studies direct culture in culture-treated polystyrene [61, 125, 135, $137,138,141,144]$ forms the commonest practice. However, the absence of comparative studies makes conclusions about the superiority of one substrate over the other impossible. Regarding the neuroinductive culture media, most studies use either the Neurobasal A or conventional primarily Dulbecco's Modified Eagle's Medium (DMEM)/F12 media in their neural differentiation protocols. These are used in conjunction with various neural supplements (most commonly the B27 $[36,125,142,144,148,149]$, but also the N2 consisting of a mixture of insulin, transferrin, progesterone, selenium, and putrescine [137] and the insulintransferrin-selenium (ITS) supplement [54] or their combinations [143]) in a serum-free approach. Alternatively, in other studies, the media are supplemented with conventional fetal calf (FCS) or Fetal Bovine Serum (FBS) at least for the first-stage preincubation phase [135]. In addition to these supplements, various growth factors, mainly Epidermal Growth Factor (EGF) and basic Fibroblast Growth Factor (FGF-2) and, to a less extent, Nerve Growth Factor (NGF), Neurotrophin 3 (NT-3), Brain-Derived Neurotrophic Factor (BDNF), Sonic Hedgehog (SHH), Glial Cell LineDerived Neurotrophic Factor (GDNF), and so forth, have been used to induce neural maturation. These are additionally supported by neuroinductive small molecules, such as beta-mercaptoethanol, 5-azacytidine, retinoic acid, dibutyryl cyclic adenosine monophosphate (dbcAMP), 3-Isobutyl-1Methylxanthine (IBMX), Dimethyl Sulfoxide (DMSO), Butylated Hydroxyanisole (BHA), forskolin, and hydrocortisone [37]. All these factors and supplements have been variously used in a number of studies, overall making it impossible to define an ideal culture microenvironment or neural induction approach.

Neural differentiation in the majority of these studies is evaluated by the expression of neural markers (such as NCAM, GFAP, GAP-43, GABA, NeuN, bIII-tubulin, synapsin, NSE, and NFL [37]), while very few have carried out functional assessments. Methods most applied to confirm functional neural transformation include the patch-clamp 
analysis of the voltage-dependent $\mathrm{Na}^{+}$or $\mathrm{K}^{+}$channels [139141, 147] and the fluorescent detection of intracellular $\mathrm{Ca}^{2+}$ flux upon stimulation with neurotransmitters [135].

Finally, a small number of studies have performed in vivo transplantation of dental MSCs to assess cell engraftment and neural marker expression [140] but also for neural disease treatment in various experimental animal models. Predifferentiated SHED-derived neurospheres were applied into the striatum of parkinsonian rats and significant improvement in behavioral impairment as compared to the implantation of control undifferentiated SHED was reported [36]. Similar results were achieved after inducing neural maturation of SHED into dopaminergic neuron-like cells and transplantation in parkinsonian rats [150]. Moreover, transplantation of neural-induced SHED in a rat Spinal Cord Injury (SCI) model led to complete recovery of hindlimb motor function [148]. All of the above studies support that neural preinduction of undifferentiated MSCs before in vivo transplantation increases the expression of neural surface receptors and therefore the grafting efficiency into the nervous system, potentially improving clinical outcomes. In a very interesting recent study, the entire apical papilla was transplanted in a SCI (hemisection) model, in comparison to transplantation of human SCAP inside fibrin hydrogels [146]. Significantly, the delivery of SCAP in their original niche (entire apical papilla) improved gait and reduced glial reactivity, as compared to the classical TE approach of cell expansion and delivery in 3D scaffolds. This highlights the importance of the 3D organization of stem cells and the surrounding microenvironment. Finally, another important set of in vivo studies were carried out by Sasaki et al. [151, 152]. They used silicone tube conduits filled with a collagen gel containing rat DPSCs and managed to bridge an experimental gap in the rat facial nerve. In a subsequent study, [152] the same group replaced the nonabsorbable silicon material with a degradable PLGA tube that was readily resorbed simultaneously promoting nerve regeneration.

3.3.2. Neurogenic Properties of Dental MSC Secretome. There is a growing body of evidence questioning the ability of dental MSCs to differentiate into functional neurons after transplantation in vivo and supports the idea that their neurogenic action is primarily exerted as in the case of angiogenesis through multiple neurotrophic factors found in their secretion products and acting in a paracrine manner (Table 1). Sakai et al. [53] showed that transplantation of DPSCs into rat SCI lesions lead to functional recovery despite only glial rather than neuronal differentiation being observed under these extreme conditions, suggesting a paracrinemediated action. Mead et al. [153] contended that DPSCs have limited potential to differentiate into neurons and fail to integrate into the retina, after transplantation. The same group found that DPSCs have a more favorable neurotrophic secretome, rich in NGF, BDNF, and NT-3, in comparison with BMMSCs [154], which is efficient in promoting survival and neuritogenesis/axogenesis of bIII-tubulin positive retinal cells after transplantation into the vitreous body of the eye; this effect was neutralized after the addition of specific
Fc-receptor inhibitors, overall suggesting a paracrine effect. Various other studies have reported on the existence of multiple neurotrophic factors, including NGF, BDNF, NT3, CNTF, GDNF, VEGF, and FGF-2 [53, 154-156] in DPSC secretome. Finally, DPSCs mobilized by G-CSF were shown to secrete a panel of neurotrophic and angiogenic factors (BDNF, GDNF, IGF, NGF, and VEGF) capable of regenerating myelinated fibers in a rat sciatic nerve defect model [157].

A series of studies on the neuroregenerative/neuroprotective properties of SHED secretome have been also published by the group of Mita et al. using various experimental neural disease models. They have found that SHED-derived, serum-free Conditioned Medium (SHED-CM) improved cognitive function in an Alzheimer's disease mouse model [158] and enhanced recovery of focal cerebral ischemia in rats after intranasal administration [159]. Additionally, SHED$\mathrm{CM}$ after intracerebral administration in mice with perinatal hypoxia-ischemia-induced brain injury generated an antiinflammatory environment, reduced tissue loss, and significantly improved the neurological outcome by converting a M1 proinflammatory to an M2 anti-inflammatory environment. The latter was primarily attributed to the combined secretion of MCP-1 and the Secreted Ectodomain of Sialic AcidBinding Ig-Like Lectin-9 (ED-Siglec-9) among 28 proteins detected in SHED-CM [160]. These results have been also validated by other groups that used SHED-CM for peripheral nerve regeneration across nerve gaps on rat sciatic nerve gap models [161]. A recent study also investigated the neuroprotective role of SHED-derived exosomes, highlighting another mechanism of their paracrine-mediated action [162].

In contrast to DPSCs and SHED, little data exist so far on the neurogenic activity of SCAP secretome. A recent study [145] demonstrated that SCAP release BDNF responsible for triggering directed axonal targeting both in vitro and in vivo, as shown by microfluidic and Matrigel implant experiments. Yu et al. also detected several neurotrophic factors in SCAP secretome, including Midkine (MDK), Pleiotrophin (PTN), Mesencephalic Astrocyte-Derived Neurotrophic Factor (MANF), Neuroblast Differentiation-Associated Protein (AHNAK), and Neurophilin 2 (NRP2).

Thus, we seem to be able to conclude that the neuroregenerative/neuroprotective properties of dental MSCs are primarily exerted through a paracrine mechanism rather than on their potential for in vivo differentiation into mature neural phenotypes. Current research trends are focusing on the preconditioning strategies to enhance neurogenic properties of dental MSC secretome, as an effective surrogate therapeutic module for stem cell transplantation therapies in the treatment of neurodegenerative diseases.

\section{Establishment of Clinical-Grade Dental MSCs and Challenges to Be Overcome before Clinical Application}

Despite the very promising results of the plethora of TE approaches published to date on the application of dental MSCs for the regeneration of various tissues, very few clinical trials mainly in the form of new methodological paradigms 
or "proof-of-concept" (phase I/II, safety/efficacy) studies have been conducted or are currently being conducted. This is in complete contrast to the rapidly growing number of clinical trials using other MSC sources (mainly BMMSCs) in treatment of various bone/articular, cardiovascular, neurological, immune, and blood pathologies (data found on https://clinicaltrials.gov/). The unique biological value of MSCs lies in the combination of differentiation potential into tissue-forming cells and the paracrine-mediated revascularization/reinnervation of the regenerated tissues, under an immunosuppressive/immunoregulatory "deck" limiting probability for adverse reactions [163].

However, one of the basic factors still hindering extensive clinical application of MSC-based therapies is among others the difficulty encountered in the ex vivo expansion of clinicalgrade, xeno-free MSCs under Good Manufacturing Practice (GMP) conditions, as described in the EU Regulation 2003/94/EC [164] (GMP is that part of quality assurance which ensures that products are consistently produced and controlled to the quality standards appropriate to their intended use and as required by the marketing authorization) and in compliance to the EU regulations (1394/2007) [165] established for the clinical use of Advanced Therapy Medicinal Products (ATMPs). These have been defined as "biological medicinal products containing or consisting of living cells or sub-cellular fractions with biological functions." AMTPs do not belong to the same category of drugs or transplants because (1) they contain viable allogeneic or autologous cells undergoing ex vivo substantial manipulations (as defined in the $\mathrm{EU}$ Regulation 1394/2007, Annex 1) and (2) they may be applied in "non-homologous use," that is, at sites not physiologically present or to perform biological functions they do not usually participate in. ATMPs are considered Cell-Based Medicinal Products (CBMPs) when containing living cells or tissues. CBMPs are "medicinal products presented as having properties for, or used in or administered to, human beings with a view to treating, preventing or diagnosing a disease in which the pharmacological, immunological or metabolic actions are carried out by cells or tissues" [166].

The recent literature on the subject has questioned whether epigenetic (e.g., homing receptor/ligand expression, cytokine/growth factor production, lineage commitment/differentiation, and programmed senescence) [20, 21] and genetic alterations (e.g., transformation, fusion, and gene transfer) occurring during expansion culture [167] may affect the therapeutic potential of stem cells in a positive or negative way. For example, the changes shown might be beneficial for site-specific application depending on the target tissues but adverse for systemic administration or vice versa. Since development of adequate numbers of high quality SCs at early passages is a prerequisite for any safe cell therapy treatment, considerable effort has been put into evaluating the consequences of the cultivation process on stem cell behavior, in particular, in developing reliable standardization protocols in the form of Standard Operating Procedures (SOPs) to be routinely applied to characterize (1) phenotypic and genetic stability of cultured dental MSCs, (2) efficacy in regenerating target tissues, (3) the permitted population doubling before senescence becomes a problem, (4) the absence of microbial, viral, fungal, mycoplasma, endotoxin, or other contamination in cultured cells, and (5) lack of tumorigenicity, toxicity, and immunogenicity, something highlighted in recent reports discussing current challenges towards clinical application of dental MSCs [168, 169]. It becomes clear from these reports that the lack of reliable characterization methods and reference standards for the evaluation of each of the above mentioned important parameters presents a major hurdle for the development of cGMP-grade cells and respective CBMPs.

Among other parameters, significant efforts have been made to replace animal sera used in conventional media due to their highly variable and often unknown composition, the immunological risks associated with serum proteins, and the potential of transmission of prion diseases [170]. Considering the significant impact of serum components in MSC maintenance and multilineage differentiation [171], efforts to replace it with autologous or allogeneic sera or with proprietary serum-free media of unknown formulations by different companies have yet to be validated for their efficacy, while their use is still restricted by the prohibitive cost. The need for development of chemically defined media which can maintain "stemness" without adversely affecting MSC function, immunoregulatory properties, and phenotype remains a significant problem to be overcome for cGMP production of MSCs [172].

Apart from establishment of clinical-grade dental MSCs, SOPs must be also developed for each of the successive steps leading to clinical application including (1) scaling-up of culture systems to produce the desired cell numbers based on the targeted therapeutic goal (upstream process); this might range from thousands to billions of cells depending on the size of the defect; a major problem to achieve this lies on the significant variability in donors and the derived cell lines, which may significantly complicate the culture scale up for high-throughput production in automated and parallel culturing systems [173]; (2) harvesting (preferably by mechanical means or by a cGMP enzymatic process using recombinant enzymes and avoiding porcine-derived trypsin or similar reagents [174]), volume reduction, and isolation of the desired cell populations (downstream possess); in particular, for cell isolation, molecular-tagging based methods have been employed to purify dental MSCs by using specific molecular markers; among these methods, fluorescenceactivated cell sorting (FACS) has been mostly used offering the advantage of multiparametric analysis for several markers [175]; although FACS systems have been recently upgraded to cGMP function [176], they have limited capacity for largescale MSC processing and significantly high costs; the same reservations can be made for the magnetism and adsorptionbased cell separation systems (MACS), which are considered to represent the "gold" standard method for cell purification, but they also have limited scalability and low efficacy to obtain high cell numbers [177]; (3) loading into appropriate carriers and preserving the final ATMP in safe conditions for immediate or later application. The latter requires robust cryopreservation processes with minimal adverse effects on cell survival and "stemness" characteristics [178]. While the conventional slow-freezing and rapid-thawing method 
in liquid nitrogen or its vapor phase is the "state-of-theart" method [179], other methods such as vitrification by the "open pulled straw" method using high cryoprotectant concentrations and ROCK inhibitor treatment together with flash freezing in liquid nitrogen have been proposed to result in higher cell survival rates [180]. However, direct contact with liquid nitrogen is considered a major drawback, as it may increase the risk of cross-contamination among samples. It still remains quite challenging that all of the above-mentioned steps, which are routinely used for research purposes, have to be optimized, upgraded, and standardized to be carried out under cGMP conditions and followed by quality assessments to secure safety and efficacy of the delivered cell-based products, making the whole process quite complicated and extremely time-consuming.

Other scientific, technological, policy, and commercial development challenges and hurdles have also to be addressed before extensive clinical application of dental MSC therapies using commercially available ATPMs to replace the biomaterial-based treatment modalities currently being used in clinical dentistry, in a solid, evidence-based manner. Another challenging point to be considered before application of dental MSC therapies in clinical dentistry is that most currently applied biomaterials and clinical methodologies have despite reported biological and technical complications high overall survival and success rates [181]. In addition, they are related to nonlife threatening diseases; therefore any novel alternative therapies need to be shown to have marked superiority to be established as clinically routine processes.

In contrast to medical literature, very limited published work exists so far on the development of clinical-grade dental MSCs and related ATMPs. In an effort to avoid serum-containing media, Tarle et al. [182] evaluated the capacity of chemically defined serum-free culture systems to effectively expand and maintain the stem cell properties of SHED and PDLSCs. Although these cells proliferated at lower rates in serum-free conditions, their multilineage differentiation potential and differential expression of 84 stem cell-associated genes showed only minor differences compared to the serum-containing medium, thus validating application of such serum-free, cGMP conditions for their safe and effective expansion. The same group proposed use of fibronectin an important serum component for optimizing the initial recovery of DPSCs from pulp biopsies under serum-free conditions [183]. Lizier et al. [184] developed a protocol of scaling-up large numbers of dental MSCs at early passages by mechanical transfer (i.e., without enzymatic treatment) into new culture dishes, thus minimizing risk of loss of their "stemness." Other novel cell culture systems for large-scale expansion such as cell factories and bioreactors have been proposed as extremely effective for other oral MSC types [169]. However, no studies exist so far on the application of these systems to dental MSC expansion, which would be important towards optimizing 3D microenvironments for targeted dental TE.

A recent report [185] described manufacturing strategies of DPSC-based ATMPs to improve safety, efficacy, and consistency of their GMP production. The authors proposed the use of impacted third molars of young healthy donors between 5 and 7 Nolla's developmental stage (i.e., from complete crown upto one third of root completed) as ideal dental MSC sources. Regarding culture conditions, they proposed explant culture instead of enzymatic dissociation, although both methods have been associated with advantages and disadvantages $[186,187]$, both being capable of recovering approximately 1 million cells from one third molar within 2 weeks. The authors also proposed the precoating of culture plates with a mixture of human placental collagens I and III, use of GMP reagents, such as TrypLe ${ }^{\circledR}$ or Accutase ${ }^{\circledR}$, and serum-free, clinical-grade culture media. Finally, they considered typical MSC markers such as CD105, CD90, and CD73 proposed by ISCT as being expressed by several MSC populations and therefore being nonspecific and proposed a large and multiparametric immunophenotyping as crucially important.

Based on the above, the process for the development of clinical-grade, xeno-free, GMP-compliant dental MSCs cultures and of the respective dental MSC-based CBPMs for preclinical and clinical evaluation is illustrated in Figure 1.

\section{Dental MSCs-Based Clinical Trials}

A significant number of studies have already been published using MSCs for the regeneration of orofacial bones, including sinus augmentation and regeneration of large- (cleft palate, alveolar ridge augmentation, maxillary replacement, mandibular fracture, replacement, and osteoradionecrosis cases) or small-size bone defects. These studies, mainly comprised of case reports/series together with few randomized controlled clinical trials (RCTs), have been systematically reviewed by Padial-Molina et al. [188] and Jakobsen et al. [189]. In the majority of these studies, BMMSCs and to a lesser extent other MSC types such as periosteum-derived MSCs or adipose tissue-derived MSCs have been used. These cells were cultured in growth media containing bovine serum, autologous serum, or other growth media and the cells either were preinduced or were not preinduced towards osteogenic differentiation before cell transplantation.

In contrast, very few clinical studies using dental MSCs have been published so far. Two successive studies by the group of Papaccio et al. [190, 191] reported on the use of autologous DPSCs, combined with a collagen sponge, to repair human mandible bone defects after extraction of third molars. The authors reported optimal vertical bone repair three months after surgery and complete restoration of periodontal tissue back to the second molars. They also evaluated the bone quality three years after transplantation and found that an entirely compact rather than spongy bone was the final outcome, without any serious clinical implications. Notably, these studies were performed in the absence of the above-described universally accepted protocols of GMPcompatible production of DPSCs. Nakashima et al. [192] published a series of studies in the potential of mobilized DPSCs to regenerate pulp in dog pulpectomized teeth and based on this they have initiated a clinical trial with pending announcement. This will provide significant insight into the potential for bringing dental MSC-based pulp regeneration into clinical reality. Finally, besides already published studies, 


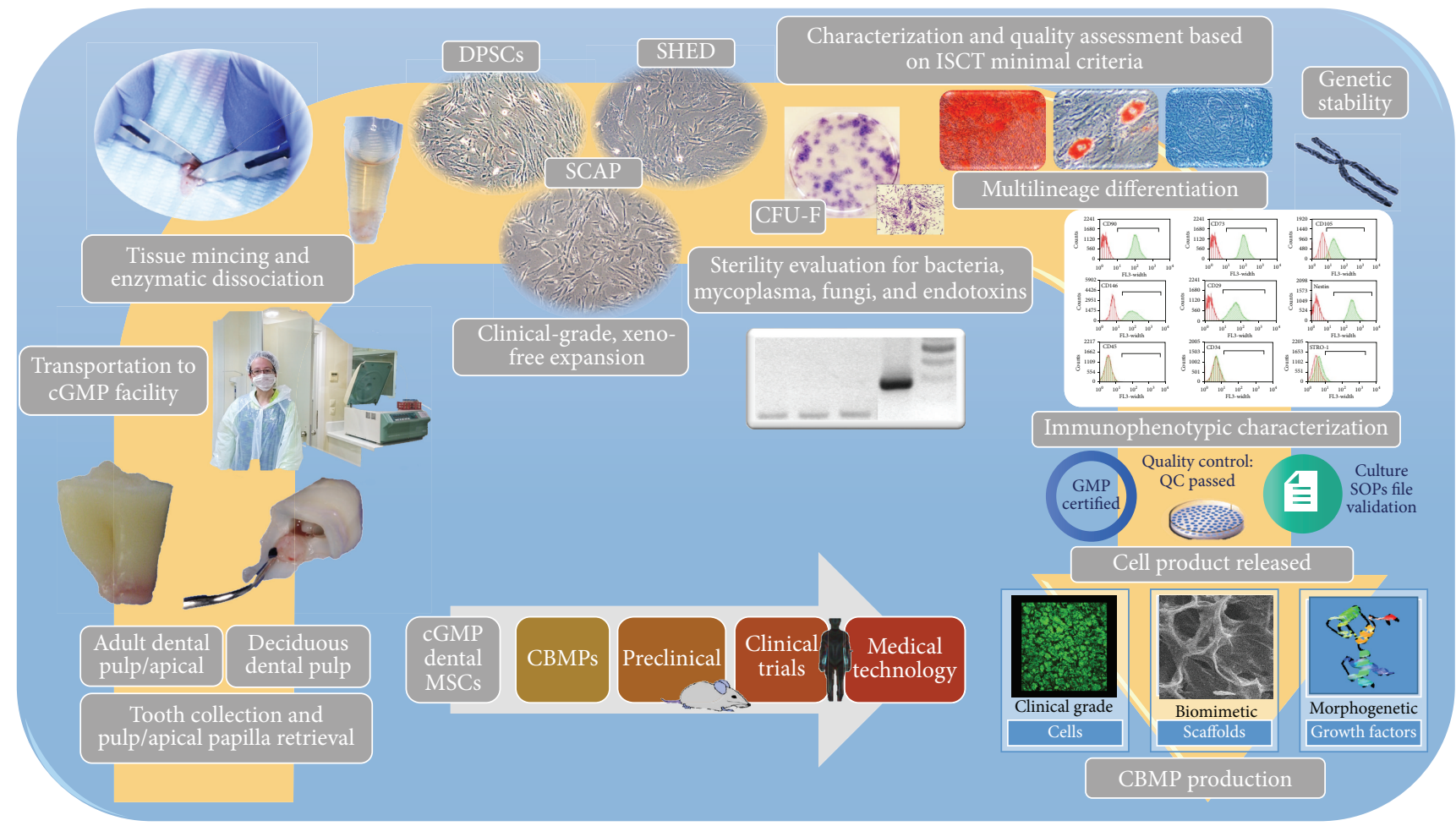

FIGURE 1: Process for the development of clinical-grade, xeno-free, GMP-compliant dental MSC cultures and of the respective dental MSCbased CBPMs for preclinical and clinical evaluation.

an electronic search in the https://clinicaltrials.gov/ database under the key words "mesenchymal stem cells" resulted in 595 clinical trials (excluding 11 which have been withdrawn), applying MSCs in various medical conditions, while only 4 clinical trials have been initiated using dental stem cells, as analytically described in Table 3.

\section{Conclusions}

Despite the constraints and limitations of current research approaches, it is safe to conclude that dental MSCs, including DPSCs, SHED, and SCAP, have been extensively studied in the past years by the dental research community using highly sophisticated in vitro and in vivo systems; this has led to a substantial understanding of their unique biological properties. As a result, bioengineering of various constituents of dental tissues such as dentin, pulp, or alveolar bone using dental MSC-based TE approaches has now been achieved. In addition, "proof-of-concept" studies for whole-tooth regeneration [193-195] are among the most fascinating recent advances, however, despite the intriguing possibilities that are opened up, there is still considerable need for further work to attain "clinical reality." Nevertheless, the major challenge still remains: how can and will the results of this extremely time-consuming, laborious, and costly research be translated into clinical therapeutic modules available to the patient; who is the final recipient of this groundbreaking technology. To consolidate the clinical utility of dental MSCs and/or their secretome in Regenerative Dentistry, there is pressing need for the initiation of well-designed RCTs aiming at the regenerative treatment of various oral tissues. This will allow a full understanding of the potential risks involved in the use of these technologies and spur efforts to surmount any problems and create a viable therapy option, a potential milestone in the application of science to clinical settings.

\section{Abbreviations}

Ac-LPL: Acetylated-Low Density LipoProtein Lipase

AHNAK: Neuroblast

Differentiation-Associated Protein

ANG: Angiogenin

ANGPT-1: Angiopoietin 1

ASCs: $\quad$ Adult Stem Cells

ATMPs: Advanced Therapy Medicinal

Products

BDNF: Brain-Derived Neurotrophic Factor

BHA: Butylated Hydroxyanisole

BMMSCs: Bone Marrow Mesenchymal Stem Cells

BMP-2: Bone Morphogenetic Protein 2

CAM: Chicken Chorioallantoic Membrane

CAMs: Cell Adhesion Molecules

CBMPs: Cell-Based Medicinal Products

CFUs: Colony Forming Units

CM: $\quad$ Conditioned Medium

CNTF: Ciliary Neurotrophic Factor 


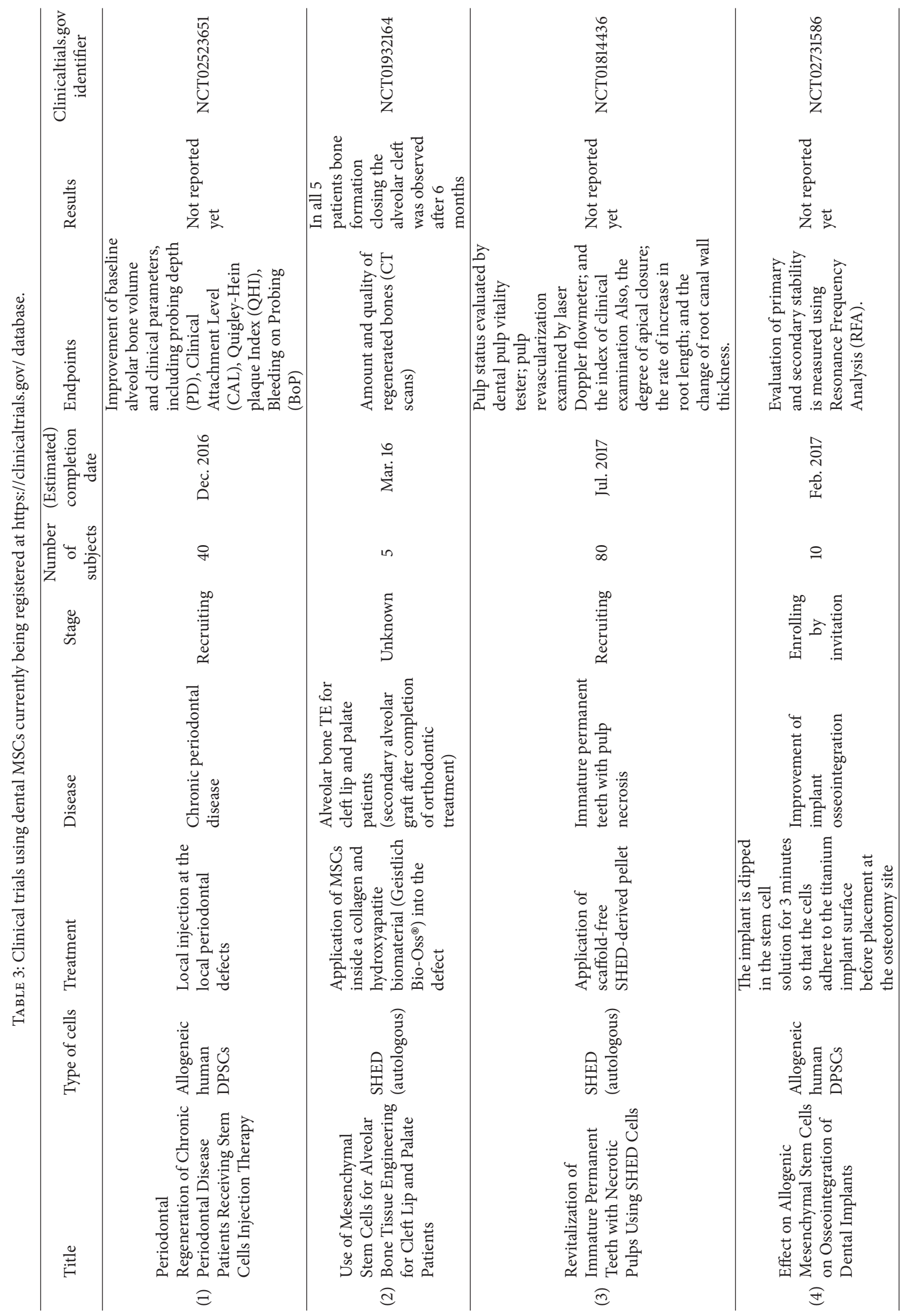




\begin{tabular}{|c|c|c|c|}
\hline CTDM: & $\begin{array}{l}\text { Cryopreserved Treated Dentine } \\
\text { Matrices }\end{array}$ & $\begin{array}{l}\text { MMP: } \\
\text { MSCs: }\end{array}$ & $\begin{array}{l}\text { Matrix Metalloproteinase } \\
\text { Mesenchymal Stem Cells or }\end{array}$ \\
\hline CXCL-16: & Chemokine (C-X-C motif) Ligand 16 & & Mesenchymal Stromal Cells \\
\hline \multirow[t]{2}{*}{ dbcAMP: } & Dibutyryl Cyclic Adenosine & NCAM-1: & Neural Cell Adhesion Molecule 1 \\
\hline & Monophosphate & NFIC: & Nuclear Factor I-C \\
\hline \multirow[t]{3}{*}{ DCX: } & Doublin or Lissencephalin-X & NFL: & Neurofilament \\
\hline & (encoded by $D C X$ gene), most known & NGF: & Nerve Growth Factor \\
\hline & as Doublecortin & NRCAM: & Neuronal Cell Adhesion Molecule \\
\hline DFSCs: & Dental Follicle Stem Cells & NRG-1-B-1: & Neuregulin Beta 1 \\
\hline DMEM: & Dulbecco's Modified Eagle's Medium & NRP-2: & Neurophilin 2 \\
\hline DMP-1: & Dentin Matrix Protein 1 & NSE: & Neuron Specific Enolase \\
\hline DMSO: & Dimethyl Sulfoxide & NT-3: & Neurotrophin 3 \\
\hline DPPIV: & Dipeptidyl Peptidase- 4 & OMSCs: & Oral Mucosa Stem Cells \\
\hline DPSCs: & Dental Pulp Stem Cells & PAI-1 (serpin E1): & Plasminogen Activator Inhibitor-1 \\
\hline DSP: & Dentin Sialoprotein & PDGF: & Platelet-Derived Growth Factor \\
\hline ECM: & Extracellular Matrix & PDLSCs: & Periodontal Ligament Stem Cells \\
\hline EDN-1: & Endothelin 1 & PEDF (serpin F1): & Pigment Epithelium-Derived Factor \\
\hline \multirow[t]{2}{*}{ ED-Siglec-9: } & Secreted Ectodomain of Sialic & PGA: & Polyglycolic Acid \\
\hline & Acid-Binding Ig-Like Lectin-9 & PIGF: & PhosphatidylInositol-Glycan \\
\hline EGF: & Epidermal Growth Factor & & Biosynthesis Class F \\
\hline \multirow[t]{3}{*}{ EG-VEGF (PK1): } & Endocrine Gland-Derived Vascular & PLA: & Polylactic Acid \\
\hline & Endothelial Growth Factor or & PRP: & Platelet-Rich Plasma \\
\hline & Prokineticin-1 & PSCs: & Periosteum-Derived Stem Cells \\
\hline EVs: & Extracellular Vesicles & PTN: & Pleiotrophin \\
\hline FBS: & Fetal Bovine Serum & PTX-3: & Pentraxin 3 \\
\hline FCS: & Fetal Calf Serum & SCAP: & Stem Cells from Apical Papilla \\
\hline FGF: & Fibroblast Growth Factor & SCF: & Stem Cell Factor \\
\hline FGFR-1: & Fibroblast Growth Factor Receptor 1 & SCI: & Spinal Cord Injury \\
\hline GABA: & Gamma-Aminobutyric Acid & SCs: & Stem cells \\
\hline GAP-43: & Growth Associated Protein 43 & SDF-1a: & Stromal Cell-Derived Factor-1a \\
\hline \multirow[t]{2}{*}{ G-CSF: } & Granulocyte-Colony Stimulating & SGSCs: & Salivary Gland-Derived Stem Cells \\
\hline & Factor & SHED: & Stem Cells from Human Exfoliated \\
\hline GDF-15: & Growth Differentiation Factor 15 & & Deciduous teeth \\
\hline \multirow[t]{2}{*}{ GDNF: } & Glial Cell Line-Derived Neurotrophic & SHH: & Sonic Hedgehog \\
\hline & Factor & SOPs: & Standard Operating Procedures \\
\hline GFAP: & Glial Fibrillary Acidic Protein & TACE: & Tumor Necrosis Factor-A Converting \\
\hline GMP: & Good Manufacturing Practice & & Enzyme \\
\hline GMSCs: & Gingival Mesenchymal Stem Cells & TDMs: & Treated Dentin Matrices \\
\hline \multirow[t]{2}{*}{ HA/TCP: } & Hydroxyapatite/Tricalcium & TE: & Tissue Engineering \\
\hline & Phosphate & TGFb: & Transforming Growth Factor Beta \\
\hline HGF: & Hepatocyte Growth Factor & TGFbRII: & Transforming Growth Factor Beta \\
\hline HMGA-2: & High-Mobility Group AT-hook 2 & & Receptor II \\
\hline \multirow[t]{2}{*}{ HUVEC: } & Human Umbilical Vein Endothelial & TIMP: & Tissue Inhibitor of Metalloproteinase \\
\hline & Cells & TSP-1: & Thrombospondin-1 \\
\hline IBMX: & 3-Isobutyl-1-Methylxanthine & uPA: & Urokinase Plasminogen Activator \\
\hline IGF-1: & Insulin-like Growth Factor 1 & VE-cadherin: & Vascular Endothelial cadherin \\
\hline \multirow[t]{2}{*}{ IGFBP: } & Insulin-like Growth Factor Binding & VEGF: & Vascular Endothelial Growth Factor \\
\hline & Protein & VEGFR-1: & Vascular Endothelial Growth Factor \\
\hline IGFR-1: & Insulin Growth Factor Receptor 1 & & Receptor I \\
\hline IL: & Interleukin & vWF: & von Willebrand Factor. \\
\hline
\end{tabular}

\section{Competing Interests}

The authors declare no competing interests.

MAP-2: $\quad$ Microtubule-Associated Protein 2

MCP-1: $\quad$ Monocyte Chemotactic Protein 1

MDK: $\quad$ Midkine

MEPE: $\quad$ Matrix Extracellular

Phosphoglycoprotein

\section{References}

[1] S. Gronthos, M. Mankani, J. Brahim, P. G. Robey, and S. Shi, "Postnatal human dental pulp stem cells (DPSCs) in vitro and 
in vivo," Proceedings of the National Academy of Sciences of the United States of America, vol. 97, no. 25, pp. 13625-13630, 2000.

[2] M. Miura, S. Gronthos, M. Zhao et al., "SHED: stem cells from human exfoliated deciduous teeth," Proceedings of the National Academy of Sciences of the United States of America, vol. 100, no. 10, pp. 5807-5812, 2003.

[3] G. T.-J. Huang, W. Sonoyama, Y. Liu, H. Liu, S. Wang, and S. Shi, "The hidden treasure in apical papilla: the potential role in pulp/dentin regeneration and bioroot engineering," Journal of Endodontics, vol. 34, no. 6, pp. 645-651, 2008.

[4] W. Sonoyama, Y. Liu, T. Yamaza et al., "Characterization of the apical papilla and its residing stem cells from human immature permanent teeth: a pilot study," Journal of Endodontics, vol. 34, no. 2, pp. 166-171, 2008.

[5] C. Morsczeck, W. Götz, J. Schierholz et al., "Isolation of precursor cells (PCs) from human dental follicle of wisdom teeth," Matrix Biology, vol. 24, no. 2, pp. 155-165, 2005.

[6] B.-M. Seo, M. Miura, S. Gronthos et al., "Investigation of multipotent postnatal stem cells from human periodontal ligament," The Lancet, vol. 364, no. 9429, pp. 149-155, 2004.

[7] Q. Zhang, S. Shi, Y. Liu et al., "Mesenchymal stem cells derived from human gingiva are capable of immunomodulatory functions and ameliorate inflammation-related tissue destruction in experimental colitis," The Journal of Immunology, vol. 183, no. 12, pp. 7787-7798, 2009.

[8] K. Marynka-Kalmani, S. Treves, M. Yafee et al., "The lamina propria of adult human oral mucosa harbors a novel stem cell population," STEM CELLS, vol. 28, no. 5, pp. 984-995, 2010.

[9] S. O. Akintoye, T. Lam, S. Shi, J. Brahim, M. T. Collins, and P. G. Robey, "Skeletal site-specific characterization of orofacial and iliac crest human bone marrow stromal cells in same individuals," Bone, vol. 38, no. 6, pp. 758-768, 2006.

[10] E. J. Arnsdorf, L. M. Jones, D. R. Carter, and C. R. Jacobs, "The periosteum as a cellular source for functional tissue engineering," Tissue Engineering-Part A, vol. 15, no. 9, pp. 2637-2642, 2009.

[11] A. Sato, K. Okumura, S. Matsumoto et al., "Isolation, tissue localization, and cellular characterization of progenitors derived from adult human salivary glands," Cloning and Stem Cells, vol. 9, no. 2, pp. 191-205, 2007.

[12] E. M. Horwitz, K. Le Blanc, M. Dominici et al., "Clarification of the nomenclature for MSC: The International Society for Cellular Therapy position statement," Cytotherapy, vol. 7, no. 5, pp. 393-395, 2005.

[13] D. J. Alongi, T. Yamaza, Y. Song et al., "Stem/progenitor cells from inflamed human dental pulp retain tissue regeneration potential," Regenerative Medicine, vol. 5, no. 4, pp. 617-631, 2010.

[14] A. Malekfar, K. S. Valli, M. M. Kanafi, and R. R. Bhonde, "Isolation and characterization of human dental pulp stem cells from cryopreserved pulp tissues obtained from teeth with irreversible pulpitis," Journal of Endodontics, vol. 42, no. 1, pp. 76-81, 2016.

[15] M. Marrelli, F. Paduano, and M. Tatullo, "Cells isolated from human periapical cysts express mesenchymal stem cell-like properties,' International Journal of Biological Sciences, vol. 9, no. 10, pp. 1070-1078, 2013.

[16] S. Shi and S. Gronthos, "Perivascular niche of postnatal mesenchymal stem cells in human bone marrow and dental pulp," Journal of Bone and Mineral Research, vol. 18, no. 4, pp. 696-704, 2003.

[17] J. Feng, A. Mantesso, C. De Bari, A. Nishiyama, and P. T. Sharp, "Dual origin of mesenchymal stem cells contributing to organ growth and repair," Proceedings of the National Academy of Sciences of the United States of America, vol. 108, no. 16, pp. 65036508, 2011.

[18] M. Dominici, K. Le Blanc, I. Mueller et al., "Minimal criteria for defining multipotent mesenchymal stromal cells. The International Society for Cellular Therapy position statement," Cytotherapy, vol. 8, no. 4, pp. 315-317, 2006.

[19] G. T.-J. Huang, S. Gronthos, and S. Shi, "Mesenchymal stem cells derived from dental tissues vs. those from other sources: their biology and role in regenerative medicine," Journal of Dental Research, vol. 88, no. 9, pp. 792-806, 2009.

[20] H. F. Duncan, A. J. Smith, G. J. Fleming, and P. R. Cooper, "Epigenetic modulation of dental pulp stem cells: implications for regenerative endodontics," International Endodontic Journal, vol. 49, no. 5, pp. 431-446, 2016.

[21] G. Gopinathan, A. Kolokythas, X. Luan, and T. G. H. Diekwisch, "Epigenetic marks define the lineage and differentiation potential of two distinct neural crest-derived intermediate odontogenic progenitor populations," Stem Cells and Development, vol. 22, no. 12, pp. 1763-1778, 2013.

[22] I. About, "Dentin regeneration in vitro: the pivotal role of supportive cells," Advances in Dental Research, vol. 23, no. 3, pp. 320-324, 2011.

[23] C. Jeanneau, P. Rufas, C. Rombouts, T. Giraud, J. Dejou, and I. About, "Can pulp fibroblasts kill cariogenic bacteria? Role of complement activation," Journal of Dental Research, vol. 94, no. 12, pp. 1765-1772, 2015.

[24] F. Chmilewsky, C. Jeanneau, P. Laurent, M. Kirschfink, and I. About, "Pulp progenitor cell recruitment is selectively guided by a C5a gradient," Journal of Dental Research, vol. 92, no. 6, pp. 532-539, 2013.

[25] F. Chmilewsky, C. Jeanneau, P. Laurent, and I. About, "Pulp fibroblasts synthesize functional complement proteins involved in initiating dentin-pulp regeneration," The American Journal of Pathology, vol. 184, no. 7, pp. 1991-2000, 2014.

[26] X. Wang, X.-J. Sha, G.-H. Li et al., "Comparative characterization of stem cells from human exfoliated deciduous teeth and dental pulp stem cells," Archives of Oral Biology, vol. 57, no. 9, pp. 1231-1240, 2012.

[27] M. F. Abdullah, S. F. Abdullah, N. S. Omar et al., "Proliferation rate of stem cells derived from human dental pulp and identification of differentially expressed genes," Cell Biology International, vol. 38, no. 5, pp. 582-590, 2014.

[28] H. Egusa, W. Sonoyama, M. Nishimura, I. Atsuta, and K. Akiyama, "Stem cells in dentistry-part I: stem cell sources," Journal of Prosthodontic Research, vol. 56, no. 3, pp. 151-165, 2012.

[29] S. Kim, S.-J. Shin, Y. Song, and E. Kim, "In vivo experiments with dental pulp stem cells for pulp-dentin complex regeneration," Mediators of Inflammation, vol. 2015, Article ID 409347, 6 pages, 2015.

[30] K. M. Fawzy El-Sayed, K. Jakusz, A. Jochens, C. Dörfer, and F. Schwendicke, "Stem cell transplantation for pulpal regeneration: a systematic review," Tissue Engineering Part B: Reviews, vol. 21, no. 5, pp. 451-460, 2015.

[31] G. Morad, L. Kheiri, and A. Khojasteh, "Dental pulp stem cells for in vivo bone regeneration: a systematic review of literature," Archives of Oral Biology, vol. 58, no. 12, pp. 1818-1827, 2013.

[32] A. H.-H. Yen and P. T. Sharpe, "Stem cells and tooth tissue engineering," Cell and Tissue Research, vol. 331, no. 1, pp. 359372, 2008. 
[33] A. Bronckaers, P. Hilkens, W. Martens et al., "Mesenchymal stem/stromal cells as a pharmacological and therapeutic approach to accelerate angiogenesis," Pharmacology and Therapeutics, vol. 143, no. 2, pp. 181-196, 2014.

[34] M. A. Saghiri, A. Asatourian, C. M. Sorenson, and N. Sheibani, "Role of angiogenesis in endodontics: contributions of stem cells and proangiogenic and antiangiogenic factors to dental pulp regeneration," Journal of Endodontics, vol. 41, no. 6, pp. 797-803, 2015.

[35] I. About, "Pulp vascularization and its regulation by the microenvironment," in The Dental Pulp: Biology, Pathology, and Regenerative Therapies, M. Goldberg, Ed., pp. 61-74, Springer, Berlin, Germany, 2014.

[36] J. Wang, X. Wang, Z. Sun et al., "Stem cells from humanexfoliated deciduous teeth can differentiate into dopaminergic neuron-like cells," Stem Cells and Development, vol. 19, no. 9, pp. 1375-1383, 2010.

[37] B. C. Heng, L. W. Lim, W. Wu, and C. Zhang, "An overview of protocols for the neural induction of dental and oral stem cells in vitro," Tissue Engineering Part B: Reviews, vol. 22, no. 3, pp. 220-250, 2016.

[38] C. Tran and M. S. Damaser, "Stem cells as drug delivery methods: application of stem cell secretome for regeneration," Advanced Drug Delivery Reviews, vol. 82-83, pp. 1-11, 2015.

[39] M. C. M. Conde, L. A. Chisini, F. F. Demarco, J. E. Nör, L. Casagrande, and S. B. C. Tarquinio, "Stem cell-based pulp tissue engineering: Variables enrolled in translation from the bench to the bedside, a systematic review of literature," International Endodontic Journal, vol. 49, no. 6, pp. 543-550, 2015.

[40] S. R. Simon, A. Berdal, P. R. Cooper, P. J. Lumley, P. L. Tomson, and A. J. Smith, "Dentin-pulp complex regeneration: from lab to clinic," Advances in Dental Research, vol. 23, no. 3, pp. 340-345, 2011.

[41] L. Xiao and M. Nasu, "From regenerative dentistry to regenerative medicine: progress, challenges, and potential applications of oral stem cells," Stem Cells and Cloning: Advances and Applications, vol. 7, pp. 89-99, 2014.

[42] J. Liu, F. Yu, Y. Sun et al., "Concise reviews: characteristics and potential applications of human dental tissue-derived mesenchymal stem cells," Stem Cells, vol. 33, no. 3, pp. 627-638, 2015.

[43] A. Di Benedetto, G. Brunetti, F. Posa et al., "Osteogenic differentiation of mesenchymal stem cells from dental bud: role of integrins and cadherins," Stem Cell Research, vol. 15, no. 3, pp. 618-628, 2015.

[44] E. Prateeptongkum, C. Klingelhöffer, and C. Morsczeck, “The influence of the donor on dental apical papilla stem cell properties," Tissue and Cell, vol. 47, no. 4, pp. 382-388, 2015.

[45] P. J. Simmons and B. Torok-Storb, "Identification of stromal cell precursors in human bone marrow by a novel monoclonal antibody, STRO-1," Blood, vol. 78, no. 1, pp. 55-62, 1991.

[46] S. Mathieu, C. Jeanneau, N. Sheibat-Othman, N. Kalaji, H. Fessi, and I. About, "Usefulness of controlled release of growth factors in investigating the early events of dentin-pulp regeneration," Journal of Endodontics, vol. 39, no. 2, pp. 228-235, 2013.

[47] A. Bakopoulou, G. Leyhausen, J. Volk, P. Koidis, and W. Geurtsen, "Comparative characterization of STRO-1(neg)/ CD146(pos) and STRO-1(pos)/CD146(pos) apical papilla stem cells enriched with flow cytometry," Archives of Oral Biology, vol. 58, no. 10, pp. 1556-1568, 2013.

[48] A. I. Caplan, "All MSCs are pericytes?" Cell Stem Cell, vol. 3, no. 3, pp. 229-230, 2008.
[49] C. V. Machado, S. T. Passos, T. M. C. Campos et al., "The dental pulp stem cell niche based on aldehyde dehydrogenase 1 expression," International Endodontic Journal, vol. 49, no. 8, pp. 755-763, 2015.

[50] M. Jamal, S. M. Chogle, S. M. Karam, and G. T. Huang, "NOTCH3 is expressed in human apical papilla and in subpopulations of stem cells isolated from the tissue," Genes \& Diseases, vol. 2, no. 3, pp. 261-267, 2015.

[51] J. Karbanová, T. Soukup, J. Suchánek, R. Pytlík, D. Corbeil, and J. Mokrý, "Characterization of dental pulp stem cells from impacted third molars cultured in low serum-containing medium," Cells Tissues Organs, vol. 193, no. 6, pp. 344-365, 2011.

[52] S. Abe, K. Hamada, M. Miura, and S. Yamaguchi, "Neural crest stem cell property of apical pulp cells derived from human developing tooth," Cell Biology International, vol. 36, no. 10, pp. 927-936, 2012.

[53] K. Sakai, A. Yamamoto, K. Matsubara et al., "Human dental pulp-derived stem cells promote locomotor recovery after complete transection of the rat spinal cord by multiple neuroregenerative mechanisms," Journal of Clinical Investigation, vol. 122, no. 1, pp. 80-90, 2012.

[54] W. Zhang, X. F. Walboomers, S. Shi, M. Fan, and J. A. Jansen, "Multilineage differentiation potential of stem cells derived from human dental pulp after cryopreservation," Tissue Engineering, vol. 12, no. 10, pp. 2813-2823, 2006.

[55] Y. Yamada, S. Nakamura, K. Ito et al., "A feasibility of useful cell-based therapy by bone regeneration with deciduous tooth stem cells, dental pulp stem cells, or bone-marrow-derived mesenchymal stem cells for clinical study using tissue engineering technology," Tissue Engineering - Part A, vol. 16, no. 6, pp. 18911900, 2010.

[56] I. Kerkis, A. Kerkis, D. Dozortsev et al., "Isolation and characterization of a population of immature dental pulp stem cells expressing OCT-4 and other embryonic stem cell markers," Cells Tissues Organs, vol. 184, no. 3-4, pp. 105-116, 2006.

[57] N. Nourbakhsh, M. Soleimani, Z. Taghipour et al., "Induced in vitro differentiation of neural-like cells from human exfoliated deciduous teeth-derived stem cells," International Journal of Developmental Biology, vol. 55, no. 2, pp. 189-195, 2011.

[58] A. Bakopoulou, A. Kritis, D. Andreadis et al., "Angiogenic potential and secretome of human apical papilla mesenchymal stem cells in various stress microenvironments," Stem Cells and Development, vol. 24, no. 21, pp. 2496-2512, 2015.

[59] M. E. Yalvac, M. Ramazanoglu, A. A. Rizvanov et al., "Isolation and characterization of stem cells derived from human third molar tooth germs of young adults: implications in neovascularization, osteo-, adipo-and neurogenesis," Pharmacogenomics Journal, vol. 10, no. 2, pp. 105-113, 2010.

[60] G. Laino, A. Graziano, R. d'Aquino et al., "An approachable human adult stem cell source for hard-tissue engineering," Journal of Cellular Physiology, vol. 206, no. 3, pp. 693-701, 2006.

[61] A. Pisciotta, G. Carnevale, S. Meloni et al., "Human dental pulp stem cells (hDPSCs): isolation, enrichment and comparative differentiation of two sub-populations integrative control of development," BMC Developmental Biology, vol. 15, article 14, 2015.

[62] R. d'Aquino, A. Graziano, M. Sampaolesi et al., "Human postnatal dental pulp cells co-differentiate into osteoblasts and endotheliocytes: a pivotal synergy leading to adult bone tissue formation," Cell Death and Differentiation, vol. 14, no. 6, pp. 1162-1171, 2007. 
[63] C.-S. Lin, H. Ning, G. Lin, and T. F. Lue, "Is CD34 truly a negative marker for mesenchymal stromal cells?" Cytotherapy, vol. 14, no. 10, pp. 1159-1163, 2012.

[64] R. Alvarez, H. L. Lee, C. Hong, and C. Y. Wang, "Single CD271 marker isolates mesenchymal stem cells from human dental pulp," International Journal of Oral Science, vol. 7, no. 4, pp. 205212, 2015.

[65] E. Flores-Torales, A. Orozco-Barocio, O. R. Gonzalez-Ramella, A. Carrasco-Yalan, K. Gazarian, and S. Cuneo-Pareto, "The CD271 expression could be alone for establisher phenotypic marker in Bone Marrow derived mesenchymal stem cells," Folia Histochemica et Cytobiologica, vol. 48, no. 4, pp. 682-686, 2010.

[66] M. Ramamoorthi, M. Bakkar, J. Jordan, and S. D. Tran, "Osteogenic potential of dental mesenchymal stem cells in preclinical studies: a systematic review using modified ARRIVE and CONSORT guidelines," Stem Cells International, vol. 2015, Article ID 378368, 28 pages, 2015.

[67] S. Shi, P. M. Bartold, M. Miura, B. M. Seo, P. G. Robey, and S. Gronthos, "The efficacy of mesenchymal stem cells to regenerate and repair dental structures," Orthodontics and Craniofacial Research, vol. 8, no. 3, pp. 191-199, 2005.

[68] G. T.-J. Huang, W. Sonoyama, J. Chen, and S. H. Park, "In vitro characterization of human dental pulp cells: various isolation methods and culturing environments," Cell and Tissue Research, vol. 324, no. 2, pp. 225-236, 2006.

[69] S. Batouli, M. Miura, J. Brahim et al., "Comparison of stem-cellmediated osteogenesis and dentinogenesis," Journal of Dental Research, vol. 82, no. 12, pp. 976-981, 2003.

[70] K. Iohara, M. Nakashima, M. Ito, M. Ishikawa, A. Nakasima, and A. Akamine, "Dentin regeneration by dental pulp stem cell therapy with recombinant human bone morphogenetic protein 2," Journal of Dental Research, vol. 83, no. 8, pp. 590-595, 2004.

[71] K. Iohara, K. Imabayashi, R. Ishizaka et al., "Complete pulp regeneration after pulpectomy by transplantation of $\mathrm{CD}_{105^{+}}$stem cells with stromal cell-derived factor-1," Tissue Engineering-Part A, vol. 17, no. 15-16, pp. 1911-1920, 2011.

[72] K. Iohara, M. Murakami, N. Takeuchi et al., "A novel combinatorial therapy with pulp stem cells and granulocyte colony stimulating factor for total pulp regeneration," Stem Cells Translational Medicine, vol. 2, no. 7, pp. 521-533, 2013.

[73] K. Iohara, M. Murakami, K. Nakata, and M. Nakashima, "Agedependent decline in dental pulp regeneration after pulpectomy in dogs," Experimental Gerontology, vol. 52, pp. 39-45, 2014.

[74] H. Horibe, M. Murakami, K. Iohara et al., "Isolation of a stable subpopulation of Mobilized Dental Pulp Stem Cells (MDPSCs) with high proliferation, migration, and regeneration potential is independent of age," PLoS ONE, vol. 9, no. 5, Article ID e98553, 2014.

[75] R. S. Prescott, R. Alsanea, M. I. Fayad et al., "In vivo generation of dental pulp-like tissue by using dental pulp stem cells, a collagen scaffold, and dentin matrix protein 1 after subcutaneous transplantation in mice," Journal of Endodontics, vol. 34, no. 4, pp. 421-426, 2008.

[76] G. T. Huang, T. Yamaza, L. D. Shea et al., "Stem/progenitor cell-mediated de novo regeneration of dental pulp with newly deposited continuous layer of dentin in an in vivo model," Tissue Engineering A, vol. 16, no. 2, pp. 605-615, 2010.

[77] X. Petridis, E. Diamanti, G. C. Trigas, D. Kalyvas, and E. Kitraki, "Bone regeneration in critical-size calvarial defects using human dental pulp cells in an extracellular matrix-based scaffold," Journal of Cranio-Maxillofacial Surgery, vol. 43, no. 4, pp. 483-490, 2015.
[78] A. De Mendonça Costa, D. F. Bueno, M. T. Martins et al., "Reconstruction of large cranial defects in nonimmunosuppressed experimental design with human dental pulp stem cells," Journal of Craniofacial Surgery, vol. 19, no. 1, pp. 204-210, 2008.

[79] T. Maraldi, M. Riccio, A. Pisciotta et al., "Human amniotic fluid-derived and dental pulp-derived stem cells seeded into collagen scaffold repair critical-size bone defects promoting vascularization," Stem Cell Research and Therapy, vol. 4, no. 3, article 53, 2013.

[80] H.-C. Liu, L.-L. E, D.-S. Wang et al., "Reconstruction of alveolar bone defects using bone morphogenetic protein 2 mediated rabbit dental pulp stem cells seeded on nanohydroxyapatite/collagen/ poly(l-lactide)," Tissue EngineeringPart A, vol. 17, no. 19-20, pp. 2417-2433, 2011.

[81] K. Ito, Y. Yamada, S. Nakamura, and M. Ueda, "Osteogenic potential of effective bone engineering using dental pulp stem cells, bone marrow stem cells, and periosteal cells for osseointegration of dental implants," The International Journal of Oral \& Maxillofacial Implants, vol. 26, no. 5, pp. 947-954, 2011.

[82] Y. Zheng, Y. Liu, C. M. Zhang et al., "Stem cells from deciduous tooth repair mandibular defect in swine," Journal of Dental Research, vol. 88, no. 3, pp. 249-254, 2009.

[83] S. Sharma, D. Srivastava, S. Grover, and V. Sharma, "Biomaterials in tooth tissue engineering: a review," Journal of Clinical and Diagnostic Research, vol. 8, no. 1, pp. 309-315, 2014.

[84] K. M. Galler, J. D. Hartgerink, A. C. Cavender, G. Schmalz, and R. N. D'Souza, "A customized self-assembling peptide hydrogel for dental pulp tissue engineering," Tissue Engineering Part A, vol. 18, no. 1-2, pp. 176-184, 2012.

[85] V. Rosa, Z. Zhang, R. H. M. Grande, and J. E. Nör, "Dental pulp tissue engineering in full-length human root canals," Journal of Dental Research, vol. 92, no. 11, pp. 970-975, 2013.

[86] R. Li, W. Guo, B. Yang et al., "Human treated dentin matrix as a natural scaffold for complete human dentin tissue regeneration," Biomaterials, vol. 32, no. 20, pp. 4525-4538, 2011.

[87] L. Jiao, L. Xie, B. Yang et al., "Cryopreserved dentin matrix as a scaffold material for dentin-pulp tissue regeneration," Biomaterials, vol. 35, no. 18, pp. 4929-4939, 2014.

[88] K. M. Galler, M. Widbiller, W. Buchalla et al., "EDTA conditioning of dentine promotes adhesion, migration and differentiation of dental pulp stem cells," International Endodontic Journal, vol. 49, no. 6, pp. 581-590, 2016.

[89] M. M. Cordeiro, Z. Dong, T. Kaneko et al., "Dental pulp tissue engineering with stem cells from exfoliated deciduous teeth," Journal of Endodontics, vol. 34, no. 8, pp. 962-969, 2008.

[90] L. Casagrande, F. F. Demarco, Z. Zhang, F. B. Araujo, S. Shi, and J. E. Nör, "Dentin-derived BMP-2 and odontoblast differentiation," Journal of Dental Research, vol. 89, no. 6, pp. 603-608, 2010.

[91] J. Y. Kim, X. Xin, E. K. Moioli et al., "Regeneration of dentalpulp-like tissue by chemotaxis-induced cell homing," Tissue Engineering-Part A, vol. 16, no. 10, pp. 3023-3031, 2010.

[92] J.-W. Yang, Y.-F. Zhang, C.-Y. Wan et al., "Autophagy in SDF$1 \alpha$-mediated DPSC migration and pulp regeneration," Biomaterials, vol. 44, pp. 11-23, 2015.

[93] M. Seo, W. Sonoyama, T. Yamaza et al., "SHED repair criticalsize calvarial defects in mice," Oral Diseases, vol. 14, no. 5, pp. 428-434, 2008.

[94] A. Behnia, A. Haghighat, A. Talebi, N. Nourbakhsh, and F. Heidari, "Transplantation of stem cells from human exfoliated 
deciduous teeth for bone regeneration in the dog mandibular defect," World Journal of Stem Cells, vol. 26, no. 4, pp. 505-510, 2014.

[95] A. Alkaisi, A. R. Ismail, S. S. Mutum, Z. A. Rifin Ahmad, S. Masudi, and N. H. Abd Razak, "Transplantation of human dental pulp stem cells: enhance bone consolidation in mandibular distraction osteogenesis," Journal of Oral and Maxillofacial Surgery, vol. 71, no. 10, pp. 1758.el-1758.e13, 2013.

[96] N. Kaukua, M. Chen, P. Guarnieri et al., "Molecular differences between stromal cell populations from deciduous and permanent human teeth," Stem Cell Research and Therapy, vol. 6, no. 1, article 59, 2015.

[97] A. Bakopoulou, G. Leyhausen, J. Volk et al., "Comparative analysis of in vitro osteo/odontogenic differentiation potential of human dental pulp stem cells (DPSCs) and stem cells from the apical papilla (SCAP)," Archives of Oral Biology, vol. 56, no. 7, pp. 709-721, 2011.

[98] A. A. Volponi, E. Gentleman, R. Fatscher, Y. W. Y. Pang, M. M. Gentleman, and P. T. Sharpe, "Composition of mineral produced by dental mesenchymal stem cells," Journal of Dental Research, vol. 94, no. 11, pp. 1568-1574, 2015.

[99] S. Wang, J. Mu, Z. Fan et al., "Insulin-like growth factor 1 can promote the osteogenic differentiation and osteogenesis of stem cells from apical papilla," Stem Cell Research, vol. 8, no. 3, pp. 346-356, 2012.

[100] W. Sonoyama, Y. Liu, D. Fang et al., "Mesenchymal stem cellmediated functional tooth regeneration in Swine," PLoS ONE, vol. 1, no. 1, article e79, 2006.

[101] T. Yagyuu, E. Ikeda, H. Ohgushi et al., "Hard tissue-forming potential of stem/progenitor cells in human dental follicle and dental papilla," Archives of Oral Biology, vol. 55, no. 1, pp. 68-76, 2010.

[102] W. Wang, M. Dang, Z. Zhang et al., "Dentin regeneration by stem cells of apical papilla on injectable nanofibrous microspheres and stimulated by controlled BMP-2 release," Acta Biomaterialia, vol. 36, pp. 63-72, 2016.

[103] J. Wang, H. Zhang, W. Zhang et al., "Bone morphogenetic protein-9 effectively induces osteo/odontoblastic differentiation of the reversibly immortalized stem cells of dental apical papilla," Stem Cells and Development, vol. 23, no. 12, pp. 14051416, 2014.

[104] W. Zhang, X. Zhang, J. Ling, X. Wei, and Y. Jian, "Osteo/odontogenic differentiation of BMP2 and VEGF gene-cotransfected human stem cells from apical papilla," Molecular Medicine Reports, vol. 13, no. 5, pp. 3747-3754, 2016.

[105] J. Zhang, Z. Wang, Y. Jiang et al., "Nuclear Factor I-C promotes proliferation and differentiation of apical papilla-derived human stem cells in vitro," Experimental Cell Research, vol. 332, no. 2, pp. 259-266, 2015.

[106] W. He, J. Zhang, Z. Niu et al., "Regulatory interplay between NFIC and TGF- $\beta 1$ in apical papilla-derived stem cells," Journal of Dental Research, vol. 93, no. 5, pp. 496-501, 2014.

[107] B. Jin and P. Choung, "Recombinant human plasminogen activator inhibitor-1 accelerates odontoblastic differentiation of human stem cells from apical papilla," Tissue Engineering Part A, vol. 22, no. 9-10, pp. 721-732, 2016.

[108] H.-H. Chang, M.-C. Chang, I.-H. Wu et al., "Role of ALK5/ Smad2/3 and MEK1/ERK signaling in transforming growth factor beta 1-modulated growth, collagen turnover, and differentiation of stem cells from apical papilla of human tooth," Journal of Endodontics, vol. 41, no. 8, pp. 1272-1280, 2015.
[109] H. Zhang, J. Wang, F. Deng et al., "Canonical Wnt signaling acts synergistically on BMP9-induced osteo/odontoblastic differentiation of stem cells of dental apical papilla (SCAPs)," Biomaterials, vol. 39, pp. 145-154, 2015.

[110] F. Sun, M. Wan, X. Xu et al., "Crosstalk between miR-34a and notch signaling promotes differentiation in apical papilla stem cells (SCAPs)," Journal of Dental Research, vol. 93, no. 6, pp. 589595, 2014.

[111] J. Li, M. Yan, Z. Wang et al., "Effects of canonical NF- $\kappa$ B signaling pathway on the proliferation and odonto/osteogenic differentiation of human stem cells from apical papilla," BioMed Research International, vol. 2014, Article ID 319651, 12 pages, 2014.

[112] C. Mu, T. Lv, Z. Wang et al., "Mechanical stress stimulates the osteo/odontoblastic differentiation of human stem cells from apical papilla via ERK 1/2 and JNK MAPK pathways," BioMed Research International, vol. 2014, Article ID 494378, 10 pages, 2014.

[113] J. Yu, Z. Deng, J. Shi et al., "Differentiation of dental pulp stem cells into regular-shaped dentin-pulp complex induced by tooth germ cell conditioned medium," Tissue Engineering, vol. 12, no. 11, pp. 3097-3105, 2006.

[114] K. Kodonas, C. Gogos, S. Papadimitriou, K. Kouzi-Koliakou, and D. Tziafas, "Experimental formation of dentin-like structure in the root canal implant model using cryopreserved swine dental pulp progenitor cells," Journal of Endodontics, vol. 38, no. 7, pp. 913-919, 2012.

[115] C. Marchionni, L. Bonsi, F. Alviano et al., "Angiogenic potential of human dental pulp stromal (stem) cells," International Journal of Immunopathology and Pharmacology, vol. 22, no. 3, pp. 699-706, 2009.

[116] R. Ishizaka, Y. Hayashi, K. Iohara et al., "Stimulation of angiogenesis, neurogenesis and regeneration by side population cells from dental pulp," Biomaterials, vol. 34, no. 8, pp. 1888-1897, 2013.

[117] A. Bronckaers, P. Hilkens, Y. Fanton et al., "Angiogenic properties of human dental pulp stem cells," PLoS ONE, vol. 8, no. 8, article e71104, 2013.

[118] K. Janebodin, Y. Zeng, W. Buranaphatthana, N. Ieronimakis, and M. Reyes, "VEGFR2-dependent angiogenic capacity of pericyte-like dental pulp stem cells," Journal of Dental Research, vol. 92, no. 6, pp. 524-531, 2013.

[119] V. T. Sakai, Z. Zhang, Z. Dong et al., "SHED differentiate into functional odontoblasts and endothelium," Journal of Dental Research, vol. 89, no. 8, pp. 791-796, 2010.

[120] L. W. Bento, Z. Zhang, A. Imai et al., "Endothelial differentiation of SHED requires MEK1/ERK signaling," Journal of Dental Research, vol. 92, no. 1, pp. 51-57, 2013.

[121] P. Hilkens, Y. Fanton, W. Martens et al., "Pro-angiogenic impact of dental stem cells in vitro and in vivo," Stem Cell Research, vol. 12, no. 3, pp. 778-790, 2014.

[122] C. Gorin, G. Y. Rochefort, R. Bascetin et al., "Priming dental pulp stem cells with fibroblast growth factor-2 increases angiogenesis of implanted tissue-engineered constructs through hepatocyte growth factor and vascular endothelial growth factor secretion," Stem Cells Translational Medicine, vol. 5, no. 3, pp. 392-404, 2016.

[123] W. L. Dissanayaka, X. Zhan, C. Zhang, K. M. Hargreaves, L. Jin, and E. H. Y. Tong, "Coculture of dental pulp stem cells with endothelial cells enhances osteo-/odontogenic and angiogenic potential in vitro," Journal of Endodontics, vol. 38, no. 4, pp. 454463, 2012. 
[124] C. Yuan, P. Wang, L. Zhu et al., "Coculture of stem cells from apical papilla and human umbilical vein endothelial cell under hypoxia increases the formation of three-dimensional vessellike structures in vitro," Tissue Engineering Part A, vol. 21, no. 5-6, pp. 1163-1172, 2015.

[125] J. Vanacker, A. Viswanath, P. De Berdt et al., "Hypoxia modulates the differentiation potential of stem cells of the apical papilla," Journal of Endodontics, vol. 40, no. 9, pp. 1410-1418, 2014.

[126] W. L. Dissanayaka, K. M. Hargreaves, L. Jin, L. P. Samaranayake, and C. Zhang, "The interplay of dental pulp stem cells and endothelial cells in an injectable peptide hydrogel on angiogenesis and pulp regeneration in vivo," Tissue Engineering-Part A, vol. 21, no. 3-4, pp. 550-563, 2015.

[127] K. Iohara, L. Zheng, H. Wake et al., "A novel stem cell source for vasculogenesis in ischemia: subfraction of side population cells from dental pulp," Stem Cells, vol. 26, no. 9, pp. 2408-2418, 2008.

[128] C. Gandia, A. N. A. Armiñan, J. M. García-Verdugo et al., "Human dental pulp stem cells improve left ventricular function, induce angiogenesis, and reduce infarct size in rats with acute myocardial infarction," Stem Cells, vol. 26, no. 3, pp. 638645, 2008.

[129] E. Eggenhofer, V. Benseler, A. Kroemer et al., "Mesenchymal stem cells are short-lived and do not migrate beyond the lungs after intravenous infusion," Frontiers in Immunology, vol. 3, article 297, 2012.

[130] S. H. Ranganath, O. Levy, M. S. Inamdar, and J. M. Karp, "Harnessing the mesenchymal stem cell secretome for the treatment of cardiovascular disease," Cell Stem Cell, vol. 10, no. 3, pp. 244-258, 2012.

[131] S. Yu, Y. Zhao, Y. Ma, and L. Ge, "Profiling the secretome of human stem cells from dental apical papilla," Stem Cells and Development, vol. 25, no. 6, pp. 499-508, 2016.

[132] G. Raposo and W. Stoorvogel, "Extracellular vesicles: exosomes, microvesicles, and friends," Journal of Cell Biology, vol. 200, no. 4, pp. 373-383, 2013.

[133] U. Pivoraitè, A. Jarmalavičiūte, V. Tunaitis et al., "Exosomes from human dental pulp stem cells suppress carrageenaninduced acute inflammation in mice," Inflammation, vol. 38, no. 5, pp. 1933-1941, 2015.

[134] M. La Noce, L. Mele, V. Tirino et al., "Neural crest stem cell population in craniomaxillofacial development and tissue repair," European Cells and Materials, vol. 28, pp. 348-357, 2014.

[135] T. Osathanon, C. Sawangmake, N. Nowwarote, and P. Pavasant, "Neurogenic differentiation of human dental pulp stem cells using different induction protocols," Oral Diseases, vol. 20, no. 4, pp. 352-358, 2014.

[136] L. Xiao and T. Tsutsui, "Characterization of human dental pulp cells-derived spheroids in serum-free medium: stem cells in the core," Journal of Cellular Biochemistry, vol. 114, no. 11, pp. 26242636, 2013.

[137] C.-C. Chang, K.-C. Chang, S.-J. Tsai, H.-H. Chang, and C.P. Lin, "Neurogenic differentiation of dental pulp stem cells to neuron-like cells in dopaminergic and motor neuronal inductive media," Journal of the Formosan Medical Association, vol. 113, no. 12, pp. 956-965, 2014.

[138] M. Kanafi, D. Majumdar, R. Bhonde, P. Gupta, and I. Datta, "Midbrain cues dictate differentiation of human dental pulp stem cells towards functional dopaminergic neurons," Journal of Cellular Physiology, vol. 229, no. 10, pp. 1369-1377, 2014.

[139] N. Urraca, R. Memon, I. El-Iyachi et al., "Characterization of neurons from immortalized dental pulp stem cells for the study of neurogenetic disorders," Stem Cell Research, vol. 15, no. 3, pp. 722-730, 2015.

[140] M. Király, K. Kádár, D. B. Horváthy et al., "Integration of neuronally predifferentiated human dental pulp stem cells into rat brain in vivo," Neurochemistry International, vol. 59, no. 3, pp. 371-381, 2011.

[141] A. Arthur, G. Rychkov, S. Shi, S. A. Koblar, and S. Gronthose, "Adult human dental pulp stem cells differentiate toward functionally active neurons under appropriate environmental cues," Stem Cells, vol. 26, no. 7, pp. 1787-1795, 2008.

[142] Y. Isobe, N. Koyama, K. Nakao et al., "Comparison of human mesenchymal stem cells derived from bone marrow, synovial fluid, adult dental pulp, and exfoliated deciduous tooth pulp," International Journal of Oral and Maxillofacial Surgery, vol. 45, no. 1, pp. 124-131, 2016.

[143] X. Feng, J. Xing, G. Feng et al., "Age-dependent impaired neurogenic differentiation capacity of dental stem cell is associated with wnt/ $\beta$-catenin signaling," Cellular and Molecular Neurobiology, vol. 33, no. 8, pp. 1023-1031, 2013.

[144] C. Yang, L. Sun, X. Li et al., "The potential of dental stem cells differentiating into neurogenic cell lineage after cultivation in different modes in vitro," Cellular Reprogramming, vol. 16, no. 5, pp. 379-391, 2014.

[145] J. F. A. De Almeida, P. Chen, M. A. Henry, and A. Diogenes, "Stem cells of the apical papilla regulate trigeminal neurite outgrowth and targeting through a BDNF-dependent mechanism," Tissue Engineering-Part A, vol. 20, no. 23-24, pp. 3089-3100, 2014.

[146] P. De Berdt, J. Vanacker, B. Ucakar et al., "Dental apical papilla as therapy for spinal cord injury," Journal of Dental Research, vol. 94, no. 11, pp. 1575-1581, 2015.

[147] P. Gervois, T. Struys, P. Hilkens et al., "Neurogenic maturation of human dental pulp stem cells following neurosphere generation induces morphological and electrophysiological characteristics of functional neurons," Stem Cells and Development, vol. 24, no. 3, pp. 296-311, 2015.

[148] Z. Taghipour, K. Karbalaie, A. Kiani et al., "Transplantation of undifferentiated and induced human exfoliated deciduous teeth-derived stem cells promote functional recovery of rat spinal cord contusion injury model," Stem Cells and Development, vol. 21, no. 10, pp. 1794-1802, 2012.

[149] G. J. Brewer, J. R. Torricelli, E. K. Evege, and P. J. Price, "Optimized survival of hippocampal neurons in B27-supplemented Neurobasal $^{\mathrm{TM}}$, a new serum-free medium combination," Journal of Neuroscience Research, vol. 35, no. 5, pp. 567-576, 1993.

[150] H. Fujii, K. Matsubara, K. Sakai et al., "Dopaminergic differentiation of stem cells from human deciduous teeth and their therapeutic benefits for Parkinsonian rats," Brain Research, vol. 1613, pp. 59-72, 2015.

[151] R. Sasaki, S. Aoki, M. Yamato et al., "Tubulation with dental pulp cells promotes facial nerve regeneration in rats," Tissue Engineering Part A, vol. 14, no. 7, pp. 1141-1147, 2008.

[152] R. Sasaki, S. Aoki, M. Yamato et al., "PLGA artificial nerve conduits with dental pulp cells promote facial nerve regeneration," Journal of Tissue Engineering and Regenerative Medicine, vol. 5, no. 10, pp. 823-830, 2011.

[153] B. Mead, A. Logan, M. Berry, W. Leadbeater, and B. A. Scheven, "Intravitreally transplanted dental pulp stem cells promote neuroprotection and axon regeneration of retinal ganglion cells after optic nerve injury," Investigative Ophthalmology and Visual Science, vol. 54, no. 12, pp. 7544-7556, 2013. 
[154] B. Mead, A. Logan, M. Berry, W. Leadbeater, and B. A. Scheven, "Paracrine-mediated neuroprotection and neuritogenesis of axotomised retinal ganglion cells by human dental pulp stem cells: comparison with human bone marrow and adiposederived mesenchymal stem cells," PLoS ONE, vol. 9, no. 10, article e109305, 2014.

[155] A. H.-C. Huang, B. R. Snyder, P.-H. Cheng, and A. W. S. Chan, "Putative dental pulp-derived stem/stromal cells promote proliferation and differentiation of endogenous neural cells in the hippocampus of mice," STEM CELLS, vol. 26, no. 10, pp. 26542663, 2008

[156] Z. Gale, P. R. Cooper, and B. A. A. Scheven, "Effects of glial cell line-derived neurotrophic factor on dental pulp cells," Journal of Dental Research, vol. 90, no. 10, pp. 1240-1245, 2011.

[157] T. Yamamoto, Y. Osako, M. Ito et al., "Trophic effects of dental pulp stem cells on Schwann cells in peripheral nerve regeneration," Cell Transplantation, vol. 25, no. 1, pp. 183-193, 2016.

[158] T. Mita, Y. Furukawa-Hibi, H. Takeuchi et al., "Conditioned medium from the stem cells of human dental pulp improves cognitive function in a mouse model of Alzheimer's disease," Behavioural Brain Research, vol. 293, pp. 189-197, 2015.

[159] T. Inoue, M. Sugiyama, H. Hattori, H. Wakita, T. Wakabayashi, and M. Ueda, "Stem cells from human exfoliated deciduous tooth-derived conditioned medium enhance recovery of focal cerebral ischemia in rats," Tissue Engineering Part A, vol. 19, no. 1-2, pp. 24-29, 2013.

[160] K. Matsubara, Y. Matsushita, K. Sakai et al., "Secreted ectodomain of sialic acid-binding Ig-like lectin-9 and monocyte chemoattractant protein-1 promote recovery after rat spinal cord injury by altering macrophage polarity," Journal of Neuroscience, vol. 35, no. 6, pp. 2452-2464, 2015.

[161] Y. Sugimura-Wakayama, W. Katagiri, M. Osugi et al., "Peripheral nerve regeneration by secretomes of stem cells from human exfoliated deciduous teeth," Stem Cells and Development, vol. 24, no. 22, pp. 2687-2699, 2015.

[162] A. Jarmalavičiūtè, V. Tunaitis, U. Pivoraitè, A. Venalis, and A. Pivoriūnas, "Exosomes from dental pulp stem cells rescue human dopaminergic neurons from 6-hydroxy-dopamineinduced apoptosis," Cytotherapy, vol. 17, no. 7, pp. 932-939, 2015.

[163] M. P. de Miguel, S. Fuentes-Julián, A. Blázquez-Martínez et al., "Immunosuppressive properties of mesenchymal stem cells: advances and applications," Current Molecular Medicine, vol. 12, no. 5, pp. 574-591, 2012.

[164] Regulation (EC) No 2003/94/EC of the European Parliament and of the Council of 8 October 2003 laying down the principles and guidelines of good manufacturing practice in respect of medicinal products for human use and investigational medicinal products for human use.

[165] Regulation (EC) No 1394/2007 of the European parliament and of the council of 13 November 2007 on advanced therapy medicinal products and amending Directive 2001/83/EC and Regulation (EC) No 726/2004.

[166] S. Pacini, "Deterministic and stochastic approaches in the clinical application of mesenchymal stromal cells (MSCs)," Frontiers in Cell and Developmental Biology, vol. 2, article 50, 2014.

[167] E. H. Javazon, K. J. Beggs, and A. W. Flake, "Mesenchymal stem cells: paradoxes of passaging," Experimental Hematology, vol. 32, no. 5, pp. 414-425, 2004.

[168] P. Hilkens, N. Meschi, P. Lambrechts, A. Bronckaers, and I. Lambrichts, "Dental stem cells in pulp regeneration: near future or long road ahead?" Stem Cells and Development, vol. 24, no. 14, pp. 1610-1622, 2015.

[169] P. G. Robey, S. A. Kuznetsov, J. Ren, H. G. Klein, M. Sabatino, and D. F. Stroncek, "Generation of clinical grade human bone marrow stromal cells for use in bone regeneration," Bone, vol. 70, pp. 87-92, 2015.

[170] A. Shahdadfar, K. Frønsdal, T. Haug, F. P. Reinholt, and J. E. Brinchmann, "In vitro expansion of human mesenchymal stem cells: choice of serum is a determinant of cell proliferation, differentiation, gene expression, and transcriptome stability," Stem Cells, vol. 23, no. 9, pp. 1357-1366, 2005.

[171] P. A. Sotiropoulou, S. A. Perez, M. Salagianni, C. N. Baxevanis, and M. Papamichail, "Characterization of the optimal culture conditions for clinical scale production of human mesenchymal stem cells," Stem Cells, vol. 24, no. 2, pp. 462-471, 2006.

[172] F. Mannello and G. A. Tonti, "Concise review: No breakthroughs for human mesenchymal and embryonic stem cell culture: Conditioned medium, feeder layer, or feeder-free; medium with fetal calf serum, human serum, or enriched plasma; serumfree, serum replacement nonconditioned medium, or ad hoc formula? All that glitters is not gold!," Stem Cells, vol. 25, no. 7, pp. 1603-1609, 2007.

[173] R. Brandenberger, S. Burger, A. Campbell, T. Fong, E. Lapinskas, and J. A. Rowley, "Cell therapy bioprocessing," BioProcess International, vol. 3, pp. 30-36, 2011.

[174] C. Capelli, O. Pedrini, R. Valgardsdottir, F. Da Roit, J. Golay, and M. Introna, "Clinical grade expansion of MSCs," Immunology Letters, vol. 168, no. 2, pp. 222-227, 2015.

[175] N. Kawashima, "Characterisation of dental pulp stem cells: a new horizon for tissue regeneration?" Archives of Oral Biology, vol. 57, no. 11, pp. 1439-1458, 2012.

[176] C. A. McIntyre, B. T. Flyg, and T. C. Fong, "Fluorescenceactivated cell sorting for CGMP processing of therapeutic cells," BioProcess International, vol. 8, no. 6, pp. 44-53, 2010.

[177] S.-Y. Lee, G.-W. Huang, J.-N. Shiung et al., "Magnetic cryopreservation for dental pulp stem cells," Cells Tissues Organs, vol. 196, no. 1, pp. 23-33, 2012.

[178] T. K. Chatzistamatiou, A. C. Papassavas, E. Michalopoulos et al., "Optimizing isolation culture and freezing methods to preserve Wharton's jelly's mesenchymal stem cell (MSC) properties: an MSC banking protocol validation for the Hellenic Cord Blood Bank," Transfusion, vol. 54, no. 12, pp. 3108-3120, 2014.

[179] S. Abbasalizadeh and H. Baharvand, "Technological progress and challenges towards cGMP manufacturing of human pluripotent stem cells based therapeutic products for allogeneic and autologous cell therapies," Biotechnology Advances, vol. 31, no. 8, pp. 1600-1623, 2013.

[180] R. Martín-Ibáñez, A. M. Strömberg, O. Hovatta, and J. M. Canals, "UNIT 1C.8 cryopreservation of dissociated human embryonic stem cells in the presence of ROCK inhibitor," Current Protocols in Stem Cell Biology, 2009.

[181] C. A. Lemos, V. E. de Souza Batista, D. A. Almeida, J. F. Santiago Júnior, F. R. Verri, and E. P. Pellizzer, "Evaluation of cementretained versus screw-retained implant-supported restorations for marginal bone loss," The Journal of Prosthetic Dentistry, vol. 115, no. 4, pp. 419-427, 2016.

[182] S. A. Tarle, S. Shi, and D. Kaigler, "Development of a serumfree system to expand dental-derived stem cells: PDLSCs and SHEDs," Journal of Cellular Physiology, vol. 226, no. 1, pp. 6673, 2011.

[183] E. J. Eubanks, S. A. Tarle, and D. Kaigler, "Tooth storage, dental pulp stem cell isolation, and clinical scale expansion without 
animal serum," Journal of Endodontics, vol. 40, no. 5, pp. 652657, 2014.

[184] N. F. Lizier, A. Kerkis, C. M. Gomes et al., "Scaling-up of dental pulp stem cells isolated from multiple niches," PLOS ONE, vol. 7, no. 6, article e39885, 2012.

[185] M. Ducret, H. Fabre, O. Degoul et al., "Manufacturing of dental pulp cell-based products from human third molars: current strategies and future investigations," Frontiers in Physiology, vol. 6, article 213, 2015.

[186] A. Bakopoulou, G. Leyhausen, J. Volk et al., "Assessment of the impact of two different isolation methods on the osteo/ odontogenic differentiation potential of human dental stem cells derived from deciduous teeth," Calcified Tissue International, vol. 88, no. 2, pp. 130-141, 2011.

[187] P. Hilkens, P. Gervois, Y. Fanton et al., "Effect of isolation methodology on stem cell properties and multilineage differentiation potential of human dental pulp stem cells," Cell and Tissue Research, vol. 353, no. 1, pp. 65-78, 2013.

[188] M. Padial-Molina, F. O’Valle, A. Lanis et al., "Clinical application of mesenchymal stem cells and novel supportive therapies for oral bone regeneration," BioMed Research International, vol. 2015, Article ID 341327, 16 pages, 2015.

[189] C. Jakobsen, J. A. Sørensen, M. Kassem, and T. H. Thygesen, "Mesenchymal stem cells in oral reconstructive surgery: a systematic review of the literature," Journal of Oral Rehabilitation, vol. 40, no. 9, pp. 693-706, 2013.

[190] R. d'Aquino, A. De Rosa, V. Lanza et al., "Human mandible bone defect repair by the grafting of dental pulp stem/progenitor cells and collagen sponge biocomplexes," European Cells and Materials, vol. 18, pp. 75-83, 2009.

[191] A. Giuliani, A. Manescu, M. Langer et al., "Three years after transplants in human mandibles, histological and in-line holotomography revealed that stem cells regenerated a compact rather than a spongy bone: biological and clinical implications," Stem Cells Translational Medicine, vol. 2, no. 4, pp. 316-324, 2013.

[192] M. Nakashima and K. Iohara, "Mobilized dental pulp stem cells for pulp regeneration: initiation of clinical trial," Journal of Endodontics, vol. 40, no. 4, pp. S26-S32, 2014.

[193] S. E. Duailibi, M. T. Duailibi, W. Zhang, R. Asrican, J. P. Vacanti, and P. C. Yelick, "Bioengineered dental tissues grown in the rat jaw," Journal of Dental Research, vol. 87, no. 8, pp. 745-750, 2008.

[194] E. Ikeda, R. Morita, K. Nakao et al., "Fully functional bioengineered tooth replacement as an organ replacement therapy," Proceedings of the National Academy of Sciences of the United States of America, vol. 106, no. 32, pp. 13475-13480, 2009.

[195] S. A. C. Modino and P. T. Sharpe, "Tissue engineering of teeth using adult stem cells," Archives of Oral Biology, vol. 50, no. 2, pp. 255-258, 2005. 

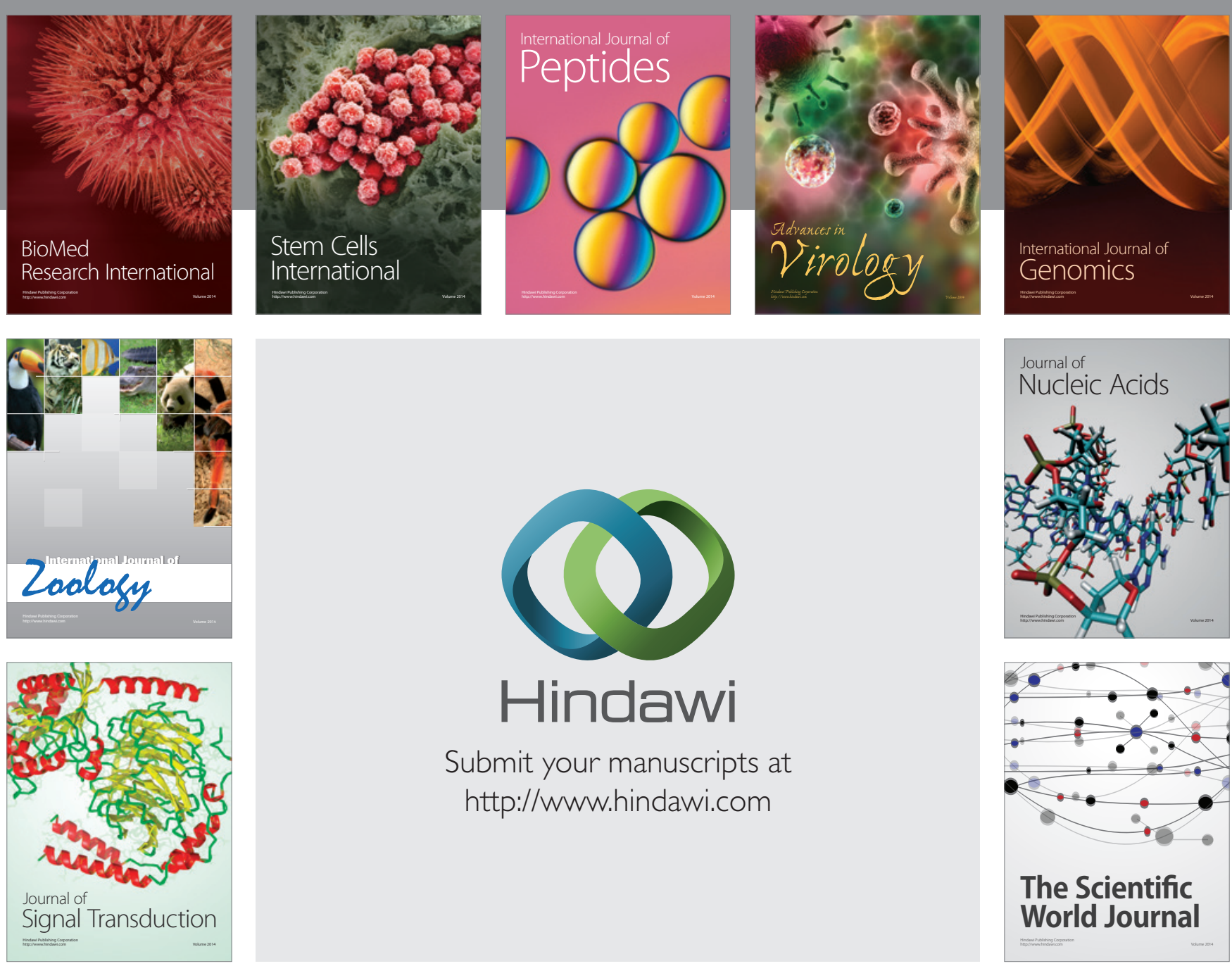

Submit your manuscripts at

http://www.hindawi.com
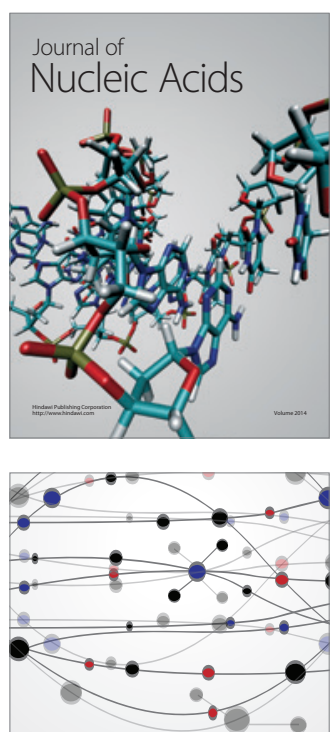

The Scientific World Journal
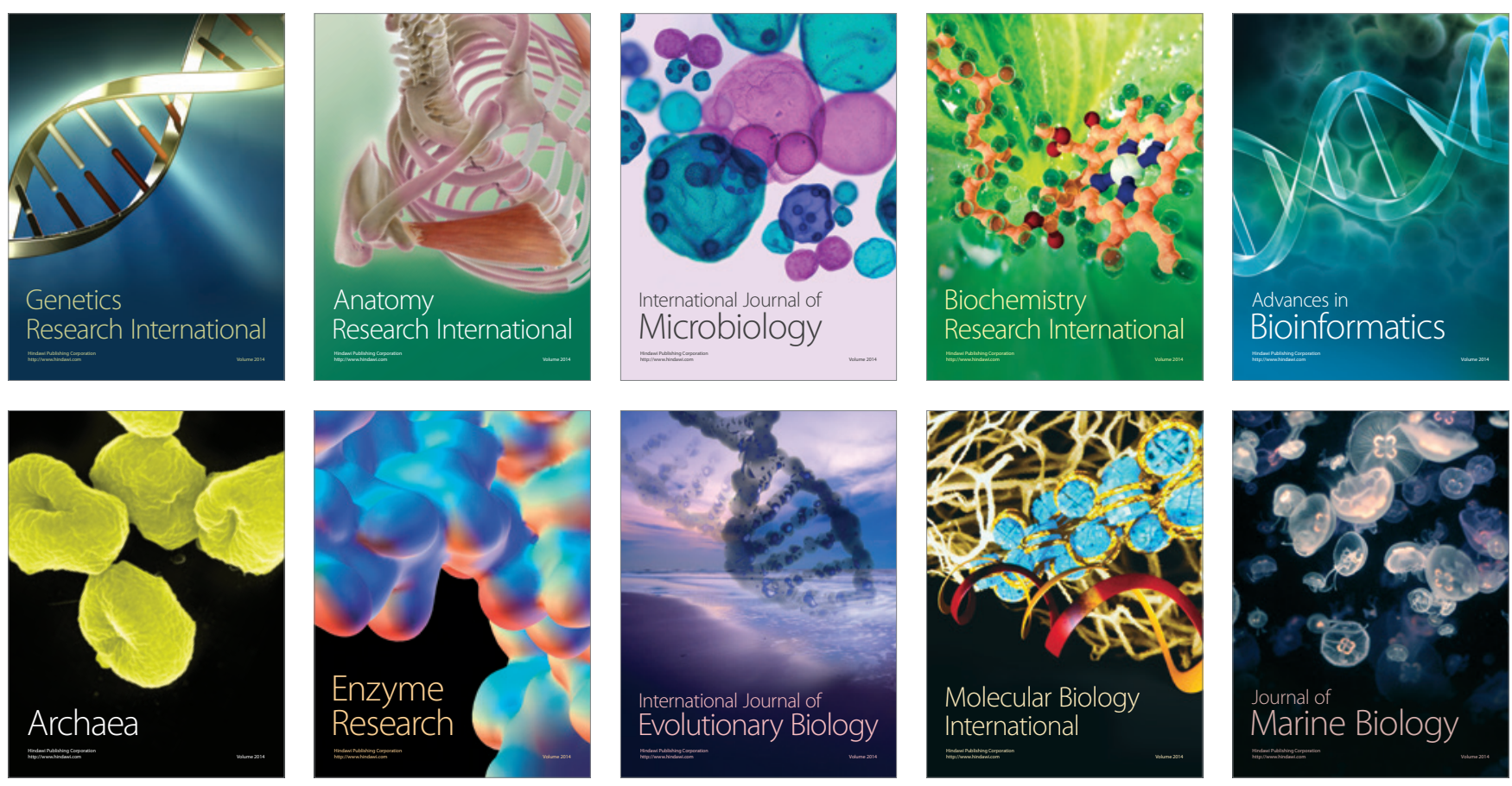